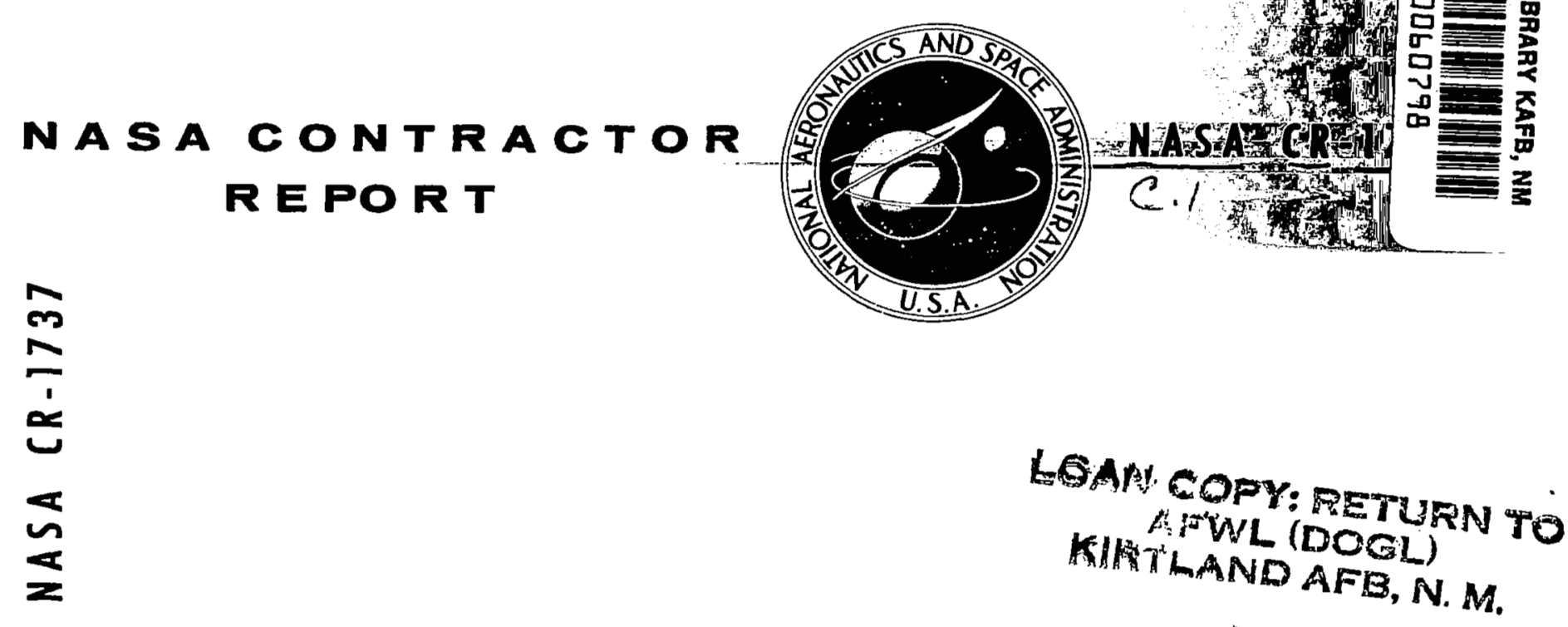

\title{
SIMULTANEOUS POLYMERIZATION
}

\section{AND MOLDING OF PYRRONE POLYMERS}

by P. E. D. Morgan and H. Scott

\section{Prepared by}

THE FRANKLIN INSTITUTE RESEARCH LABORATORIES

Philadelphia, Pa. 19103

for Langley Research Center

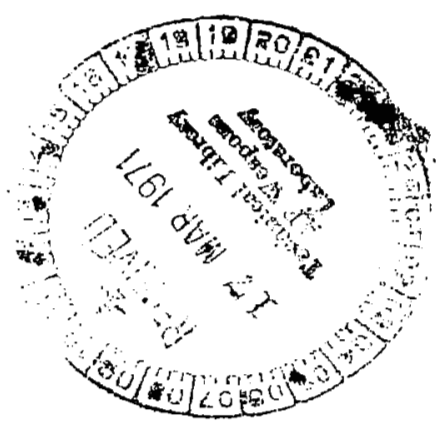

NATIONAL AERONAUTICS AND SPACE ADMINISTRATION - WASHINGTON, D. C. - MARCH 197I 


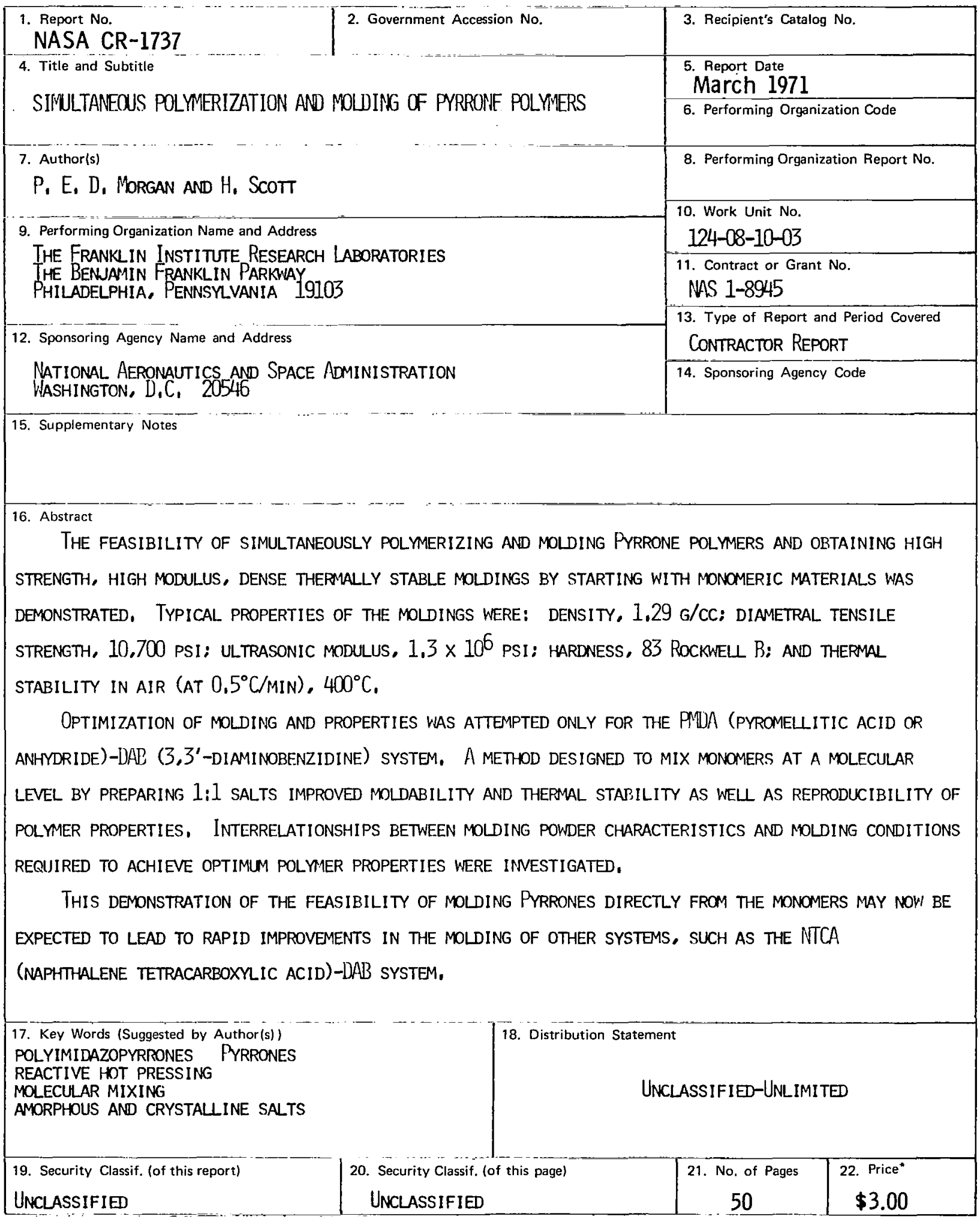

*For sale by the National Technical Information Service, Springfield, Virginia 22151 


\section{LIST OF CONTENTS}

Section Title

Page

LIST OF FIGURES LIST OF TABLES

1. INTRODUCTION

2. EXPERIMENTAL

\subsection{Materials}

2.1.1 Monomers



2.2 Mixtures, Blends and Salts of Monomers . . . . 3

2.2.1 Ballmilled Mixtures . . . . . . . . . 3

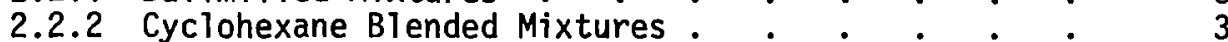

2.2.3 Freeze-Dried Mixtures . . . . . . . . 3

2.2 .4 Amorphous Salts . . . . . . . . . . 3

2.2 .5 Crystalline Salts $. \quad . \quad . \quad . \quad . \quad . \quad . \quad . \quad . \quad . \quad . \quad 4 \quad 4$

2.3 Preevaluation of Molding Powders . . . . . . . 4

2.4 Molding Equipment and Procedures . . . . . . . . 5

2.5 Testing of Molded Products . . . . . . . . . $\quad . \quad 8$



3.1 Thermogravimetric Analysis (TGA) of Starting Materials 9

3.2 Molding Performance. . . . . . . . 9

3.2.1 Molding Behavior of Unpurified PMDA-DAB . . . . 9

3.2.2 Molding Behavior of Purified Grades of PMDA-DAB : $\quad 20$

3.2.3 Molding Using the Linear Shrinkage Method . • 22

3.3 T.G.A. Results on Moldings . . . . . . . . 22

3.4 Ultrasonic Modulus Results . . . . . . . . . . 24

3.5 Hardness Results . . . . . . . . . . . 27

3.6 Diametral Strength Results . . . . . . . . 28

4. GENERAL RESULTS AND DISCUSSION OF OTHER SYSTEMS . $\quad$ • 29

4.1 Preevaluation of Molding Powders Other Than PMDA-DAB . 29

4.2 Molding Results . . . . . . . . . . . . 29

4.3 T.G.A. Results On Moldings . . . . . . . . 33

4.4 Ultrasonic Modulus Results . . . . . . . . . 33

4.5 Hardness Results



5. SUMMARY TABLES OF RESULTS •

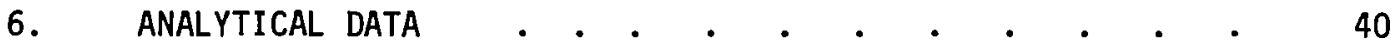

7. SUMMARY CONCLUSIONS • . . . . . . . . . . . 41

APPENDIX $\quad . \quad . \quad . \quad . \quad . \quad . \quad . \quad . \quad . \quad .42$

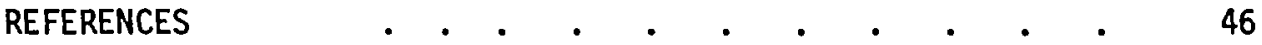




\section{LIST OF FIGURES}

Fig. No.

Title

Page

1. DIAGRAMMATIC VIEW OF THE HOT PRESS • . • . • • . . 6

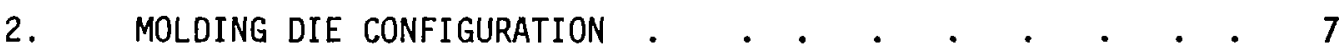

3. THERMOGRAVIMETRIC $\left(5^{\circ} \mathrm{C} / \mathrm{min}, \mathrm{N}_{2}\right)$ ANALYSIS OF. THREE $1: 1 \quad 10$ PMDA-DAB COMPOSITIONS INCLUDING THE AMORPHOUS SALT (PMA-DAB)

4. T.G.A. $\left(5^{\circ} \mathrm{C} / \mathrm{min}, \mathrm{N}_{2}\right)$ OF ORANGE CRYSTALLINE, PMA-DAB, SALT . 11

5. TYPICAL SHRINKAGE BEHAVIOR OF MILLED PMDA-DAB AT CON-



6. SHRINKAGE WHEN CONTROLLED BY THE "LINEAR SHRINKAGE" METHOD 14

7. DENSITIES ACHIEVED IN SAMPLES FROM MILLED PMDA-DAB AS A FUNC- 15 TION OF APPLIED CONSTANT PRESSURE AND RATE OF RISE OF TEMPERATURE (UP TO $450^{\circ} \mathrm{C}$-HELD FOR $1 \mathrm{HR}$ ). BEST MOLDING REGION ILLUSTRATED.

8. DENSITIES ACHIEVED IN SAMPLES FROM BLENDED PMDA-DAB AS A

FUNCTION OF APPLIED CONSTANT PRESSURE AND RATE OF RISE OF TEMPERATURE (UP TO $450^{\circ} \mathrm{C}-$ HELD FOR $1 \mathrm{HR}$ ). BEST MOLDING REGION ILLUSTRATED.

9. DENSITIES ACHIEVED IN SAMPLES FROM FIRST BATCH OF AMORPHOUS PMA-DAB SALT AS A FUNCTION OF APPLIED CONSTANT PRESSURE AND RATE OF RISE OF TEMPERATURE (UP TO $450^{\circ} \mathrm{C}-\mathrm{HELD}$ FOR $1 \mathrm{HR}$ ). BEST MOLDING REGION ILLUSTRATED.

10. DENSITIES ACHIEVED IN SAMPLES FROM SECOND BATCH OF AMORPHOUS 19 PMA-DAB SALT AS A FUNCTION OF APPLIED CONSTANT PRESSURE AND RATE OF RISE OF TEMPERATURE (UP TO $450^{\circ} \mathrm{C}-\mathrm{HELD}$ FOR 1 HR.) .

11. TYPICAL SHRINKAGE BEHAVIOR OF ORANGE CRYSTALLINE 1:1 SALT OF 21 PMA-DAB AT CONSTANT PRESSURE

12. T.G.A. OF A MOLDING FROM MILLED PMDA-DAB DONE IN AIR AT $10^{\circ} \mathrm{C} / \mathrm{min}$ and $0.5^{\circ} \mathrm{C} / \mathrm{min}$ SHOWING NEED FOR SLOWER RATE OF MEANINGFUL INTERPRETATION

13. T.G.A.'s (AIR, $0.5^{\circ} \mathrm{C} / \mathrm{min}$ ) OF VARIOUS MOLDINGS, MADE AS INDI- 25 CATED, OF PMDA (OR PMA)-DAB 


\section{LIST OF FIGURES \\ (continued)}

Fig. No.

Title

$\underline{\text { Page }}$

14. ENLARGED VIEW OF INSERT OF FIGURE 13. • • • • • • • 26

15. T.G.A. $\left(5^{\circ} \mathrm{C} / \mathrm{min}, \mathrm{N}_{2}\right)$ OF BTDA-DAB MOLDING COMPOSITIONS • 30

16. T.G.A. $\left(5^{\circ} \mathrm{C} / \mathrm{min}, \mathrm{N}_{2}\right)$ OF PURPLE CRYSTALLINE SALT OF NTCA-DAB 31

17. T.G.A. $\left(5^{\circ} \mathrm{C} / \mathrm{min}, \mathrm{N}_{2}\right)$ OF OLIVE GREEN CRYSTALLINE DANA . • 31

18. T.G.A. $\left(5^{\circ} \mathrm{C} / \mathrm{min}, \mathrm{N}_{2}\right.$ AND AIR) OF 4-AMINO PHTHALIC ACID. . 32 


\section{LIST OF TABLES}

Table No.

Title

Page

I

TEMPERATURE OF TOP THERMAL STABILITY IN AIR $\left(0.5^{\circ} \mathrm{C} / \mathrm{min}\right) 34$

OF HOLDINGS OF VARIOUS MIXES AND MONOMERS

II SUMMARY OF THE MOLDING AND PROPERTIES OF SOME OF THE

35

BETTER SAMPLES OF PMDA DAB

III SIGNIFICANT MOLDING AND PROPERTIES OF THE BTDA-DAB AND 38 NTCA-DAB SYSTEMS

IV PYRRONE MOLDINGS AS SUPPLIED TO NASA PREPARED FROM

39

PMDA-DAB SALTS 


\section{SIMULTANEOUS POLYMERIZATION AND MOLDING OF PYRRONE POLYMERS}

By P. E. D. Morgan and H. Scott

The Franklin Institute Research Laboratories

\section{INTRODUCTION}

Condensed polyheterocyclic aromatic polymers offer great promise for high temperature application. In particular, the PYRRONES (polyimidazopyrrolones), a class of polymer developed at the NASA/Langley Research Center, seemed to possess the necessary properties desirable for polymer moldings and this supposition was borne out in practice during the course of this work. A good survey of Pyrrone chemistry is contained in Ref. 1 and we will not attempt to duplicate this here. The normal route to a Pyrrone molded product has been through the molding of either prepolymers, such as polyamic acids, or low oligomers. The preparation of these precursors requires very careful synthetic work, which is time-consuming and expensive. Moreover, molded products by these routes have not generally shown optimum properties due to the difficulty of removing gaseous solvent remnants, which are strongly absorbed by the prepolymers, producing material with less than optimum properties such as stability, density, tensile strength and modulus.

The objective of this program, therefore, was to determine if a solid state reactive hot-pressing technique could be applied to organic monomers in much the same way as has recently been applied to ceramic materials (Refs. 2 and 3 ). With this molding technique solid monomers would be converted directly in one step to molded end products of thermostable plastics which should yield superior polymer properties and avoid many of the practical difficulties associated with wet prepolymer preparation and molding methods.

It was anticipated, in view of the complexity of this forming process, involving interacting gases, monomers, oligomers and polymers at various stages, that a close study of the effects of rate of rise of temperature, pressure (constant or variable) and degree of mixing would be needed. The complex relationships between these variables were confirmed in practice.

\section{EXPERIMENTAL}

\subsection{Materials}

\subsubsection{Monomers}

Commercial grades of pyromellitic anhydride (PMDA) (Princeton Chemical Research. Inc.), 3,3',4,4'-benzophenonetetracarboxylic anhydride (BTDA from Gulf $0 i 1$ Co.), and $3,3^{\prime}$-diaminobenzidine (DAB,-from Burdick and Jackson Co.) were used as received in most cases after finding that purification of these 
compounds, as indicated below, yielded few if any improvements in the moldability, elemental content and physical properties of resulting polymers. A notable exception was $1,4,5,8$-naphthalene tetracarboxylic anhydride (NTCA) obtajned from several suppliers. We succeeded in recovering usefut material only on purification of a small amount of a no longer available grade from the Aldrich Chemical Co. early in the program.

\subsubsection{Monomer Purification}

PMDA and BTDA

The anhydrides were placed in a large sublimator having a stainless steel screen with a center hole positioned between the anhydride and the cold finger, which was cooled by an acetone-dry ice bath. In a typical run, $29 \mathrm{~g}$ of sublimate was obtained from a charge of $50 \mathrm{~g}$ at $50 \mu$ vacuum using a $200-220^{\circ} \mathrm{C}$ oil bath.

NTCA *

Fifty grams of $1,4,5,8-$ naph thalenetetracarboxylic acid was mixed with $150 \mathrm{~g}$ potassium hydroxide and $15 \mathrm{~g}$ activated carbon to which $600 \mathrm{ml}$ of hot distilled water was slowly added to dissolve the mixture. The hot solution was filtered and then treated with $400 \mathrm{ml}$ of $5 \%$ potassium permanganate solution. After heating at $90^{\circ} \mathrm{C}$ for 30 minutes, the solution was filtered and the filtrate acidified with concentrated hydrochloric acid. The precipitate was filtered off and redissolved in $500 \mathrm{ml}$ of water which was made basic with $20 \%$ sodjum hydroxide. The solution was again treated with $15 \mathrm{~g}$ of activated carbon, filtered, and the filtrate acidified with concentrated hydrochloric acid. The white filtrate was washed with water containing a trace of hydrochloric acid and dried in vacuo. Twenty-five grams of purified NTCA were recovered.

$\mathrm{DAB}$

Forty grams of 3,3'-diaminobenzidine was added to a mixture of $750 \mathrm{ml}$ distilled water and the same amount of methanol which had been saturated with nitrogen. The mixture was heated to reflux under nitrogen. After most of the solid had dissolved, $20 \mathrm{~g}$ of activated carbon was added. The hot solution was filtered through diatomaceous silica. The filtrate, kept under nitrogen, was cooled immediately in an ice bath. The off-white crystals were filtered off, washed with water and methanol, and dried in vacuo at room temperature for one week. A yield of $27 \mathrm{~g}, \mathrm{~m} . \mathrm{p} .173-4^{\circ} \mathrm{C}$, was obtained.

* This purification procedure is similar to that described by $J$. A. Webster and E. S. Blake of Monsanto Research Corp. in Interim Report of May 1966 under Air Force Contract No. 33(615) 2648, as supplied by Dr. R. L. Van Deusen, Non-Metallic Materials Laboratory, Wright-Patierson Air Force Base, Dayton, Ohio. 


\subsection{Mixtures, Blends and Salts of Monomers}

\subsubsection{Ballmilled Mixtures}

$D A B$, as received, was in a coarse granular form and was first ballmilled separately with alumina balls. When finely powdered, the mixture with unmilled PMDA was made by rolling equimolar amounts of each powder without balls. Other compositions were made in a similar manner.

\subsubsection{Cyclohexane Blended Mixtures}

Typically, DAB, as already finely powdered by ballmilling, was mixed with the appropriate quantity of finely divided PMDA and the mixture blended for 15 minutes in cyclohexane in a large blender, at high speed. This method achieved superior, more intimate mixing.

\subsubsection{Freeze-Dried Mixtures}

$D A B$ and PMDA

Five grams of sublimed PMDA were mixed with $100 \mathrm{ml}$ of distilled pyridine. This suspension was poured into a cooled solution of $4.9 \mathrm{~g}$ of pure $D A B$ in $100 \mathrm{ml}$ of water and $80 \mathrm{ml}$ of distilled dioxane. After $70 \mathrm{ml}$ of distilled water was added, the mixture was dropped into liquid nitrogen. The solvent was removed from the solid product in vacuo. After complete drying, $9.6 \mathrm{~g}$ of a yellow solid was obtained.

The foregoing procedure was also followed in preparing freezedried salts of the crude monomers.

$D A B$ and $B T D A$

a) A solution of $4.8 \mathrm{~g} \mathrm{BTDA}$ and $3.2 \mathrm{~g} \mathrm{DAB}$ in $200 \mathrm{ml}$ hot dioxane was filtered and added dropwise to liquid nitrogen. The solid precipitate was kept frozen while the solvent was removed in vacuo.

b) A solution of $4.8 \mathrm{~g}$ BTDA in $100 \mathrm{ml}$ pyridine was added to a solution of $3.2 \mathrm{~g} D A B$ in $100 \mathrm{ml}$ pyridine. After $20 \mathrm{ml}$ water was added to retard polymerization, the solution was added dropwise to liquid nitrogen. The solvent was removed in vacuo from the frozen precipitate.

\subsubsection{Amorphous Salts}

DAB and BTDA

A solution of $10 \mathrm{~g}$ BTDA in $100 \mathrm{ml}$ hot water was added to a suspension of $6.6 \mathrm{~g}$ pure $D A B$ in $100 \mathrm{ml}$ water in a $50^{\circ} \mathrm{C}$ oil bath. The yellow precipitate which formed on cooling weighed $16.5 \mathrm{~g}$ after isolation.

Anal.: Calc. for $\mathrm{C}_{29} \mathrm{H}_{24} \mathrm{~N}_{4} \mathrm{O}_{9}(\%) ; \mathrm{C}, 60.83 ; \mathrm{H}, 4.22 ; \mathrm{N}, 9.78$.

Found: $\mathrm{C}, 59.60 ; \mathrm{H}, 4.54 ; \mathrm{N}, 10.70$. 
$D A B$ and PMDA

A solution of $20 \mathrm{~g}$ crude PMDA in $150 \mathrm{ml}$ distilled water was refluxed for two hours, then poured into a vigorousiy stirred hot solution of $20 \mathrm{~g} \mathrm{DAB}$ in $200 \mathrm{mi}$ distilled water and the same amount of methanol. The DAB solution was kept under nitrogen. After mixing, a yellow precipitate appeared immediately. It was filtered off, washed with water and dried to give $43 \mathrm{~g}$ of amorphous solid product which slowly darkened on standing. Anal.: Cal. for $\mathrm{C}_{22} \mathrm{H}_{20} \mathrm{~N}_{4} \mathrm{O}_{8}(\%) ; \mathrm{C}, 56.41 ; \mathrm{H}, 4.30 ; \mathrm{N}, 11.96$.

Found: $\mathrm{C}, 56.32 ; \mathrm{H}, 4.22 ; \mathrm{N}, 17.84$.

\subsubsection{Crystalline Salts}

DAB and PMDA

A solution of $54.5 \mathrm{~g}$ crude PMDA in 1.2 liters distilled water which had been heated to reflux for two hours was added while still hot to a vigorously stirred solution of $54.7 \mathrm{~g}$ crude $D A B$ in a mixture of 2 liters distilled water and $500 \mathrm{ml}$ methanol kept under a nitrogen atmosphere. The DAB solution was seeded before the addition with crushed orange crystals which had been prepared in earlier trial runs. The orange product was filtered off, washed with water and methanol and dried in vacuo to give $111 \mathrm{~g}$ (95\% yield). Analysis of 1 lb. sample supplied to NASA/Langley: Calc. for $\mathrm{C}_{22} \mathrm{H}_{20} \mathrm{~N}_{4} \mathrm{O}_{8}(\%) ; \mathrm{C}, 56.41 ; \mathrm{H}, 4.30 ; \mathrm{N}, 11.96$. Found: $\mathrm{C}, 56.18 ; \mathrm{H}, 4.37$; $\mathrm{N}, 11.77$.

NTCA and DAB

A mixture of $42.8 \mathrm{~g}$ of crude $D A B$ and 2.5 liters distilled water was heated to reflux with stirring in a nitrogen atmosphere and then filtered directly into a preheated 1 gallon stainless steel blender. A slurry of $60.8 \mathrm{~g}$ purified NTCA in 7 liter of distilled water which had been heated to reflux was poured into the stirred DAB solution. After 15 minutes of stirring, the reaction mixture was chilled with an ice bath and refrigerated overnight. A finely divided dark purple solid was filtered off, washed with water and methanol and dried in vacuo. Calc. for $\mathrm{C}_{26} \mathrm{H}_{22} \mathrm{~N}_{4} \mathrm{O}_{8}: \mathrm{C}, 60.23$; $\mathrm{H}, 4.27 ; \mathrm{N}, 10.81$. Found: $\mathrm{C}, 60.38 ; \mathrm{H}, 4.10 ; \mathrm{N}, 10.56$.

\subsection{Preevaluation of Molding Powders}

About midway in the program we found it useful to analyze the molding materials by thermogravimetric analysis (TGA) and to a lesser extent by differential scanning calorimetry (DSC), using a du Pont 950 Thermogravimetric Analyzer. With DSC, for instance, it was quickly determined that samples of NTCA obtained from various suppliers yielded products with properties that differed from those of the product recovered from an early sample of a no longer available Aldrich grade. This was the only NTCA sample found to be useful for molding purposes.

TGA under nitrogen was found to be extremely useful for determining the temperatures of water loss for materials to be molded and whether the materials lost the correct amount of water for conversion to polymer. To avoid 
volatilization of the monomers in the stream of nitrogen, e.g. on disintegration of heated particles, it was found best to cover the sample cup with an inverted cup. As shown later, the moldability of various samples such as mechanical mixtures, blends and salts, and the quality of resulting moldings, reflected marked differences seen in the thermogravimetric analysis of these starting materials.

\subsection{Molding Equipment and Procedures}

A hot-pressing unit with automatic control and recording of temperature and pressure was used.

Figure 1 shows the operative portion of the apparatus, a typical experimental hot-pressing setup, standing on a Loomis hydraulic press. The die configuration used is shown in Fig. 2, where provision for the escape of water vapors or other gases is made by using a graphite insert sleeve of UTtra Carbon's UF-4S high purity porous graphite. The die and punches are of standard stainless steel. Resistance heating is by means of Kanthal windings and the heating rate is controlled by a temperature programmer. Pressure may be maintained at a fixed value if desired by a hydraulic pump equipped with variable bypass valves.

"Double ended" pressing is obtained by use of the floating die principle as depicted. This configuration is achieved by cold pressing before inserting the filled die into the furnace. Platen movement during hot pressing which is related to the shrinkage of the sample is registered on a double pen chart recorder via the output of a linear differential transformer calibrated against the dial gauge. Corrections for thermal expansion of the various parts may be obtained if necessary by blank runs under the same conditions. The die temperature, as indicated by the thermocouple, is registered alongside the same chart recorder.

Two types of molding schedules have been used in this work. In the simpler case, a constant predetermined pressure is applied at room temperature to the sample within the die. The temperature is raised at a constant predetermined rate up to $450^{\circ} \mathrm{C}$ and then held constant for one hour. In a few instances other top temperatures have also been used. Normally, the pressure is completely removed at this point and the furnace allowed to cool slowly to room temperature.

A second molding approach referred to as the "linear method" has often been used for mixtures in the initial stages of study. In this method, temperature, as before, rises from room temperature linearly to $450^{\circ} \mathrm{C}$. However, the pressure is varied manually to produce a linear shrinkage as perceived upon the chart recorder. The extent of this linear shrinkage must be roughly predetermined for each mixture. With this knowledge, a straight line is drawn on the chart recorder, and the operator continuousiy adjusts the pressure applied by the pump so that the recorder pen follows the shrinkage line up to $450^{\circ} \mathrm{C}$; the sample is then, as before, maintained at $450^{\circ} \mathrm{C}$ at the pressure that was used when the sample reached $450^{\circ} \mathrm{C}$. Typically, with this method, a high pressure was applied to the sample at room temperature, not exceeding 12,000 psi which was arbitrarily chosen as the top pressure to be used, being near the maximum that the graphite lining material can withstand. 




FIGURE 1. DIAGRAMMATIC VIEW OF THE HOT PRESS 




(1) THERMOCOUPLE

(2) $1 / 8^{\prime \prime}$ U.F. $-4 S$ SPACERS

(3) SAMPLE

(4) STAINLESS STEEL DIE

(5) 1/8" U.F.-4S GRAPHITE SLEEVE

(6) STAINLESS STEEL PUNCH

FIGURE 2. MOLDING DIE CONFIGURATION 
As the temperature rises and the reaction and plasticity of the monomer materials increase, the pressure was lowered, often to as low as only a few hundred psi at times. At some temperatures, when polymerization had occurred, higher pressures were again necessary to maintain the linear shrinkage, and usually by $450^{\circ} \mathrm{C}$ the pressure was again about 7-10,000 psi.

Towards the end of the project, an automatic linear shrinkage controller was installed, which operates by comparing the output of a linearly increasing EMF source with the output of the linear differential transformer attached to the platen and operating a mechanical device or the pump which automatically adjusts the pressure. The linear method has certain advantages which will be explained later.

\subsection{Testing of Molded Products}

A typical molding produced by aforementioned methods was a cylinder $3 / 4^{\prime \prime}$ in diameter by about $3 / 8^{\prime \prime}$ long. Good samples were non-porous and densities on these were measured using the Archimedes displacement method in water. Porous samples of lesser interest, may be measured by geometric methods. Hardness values on the high temperature plastic specimens were measured by two methods; in the early work, microhardness measurements, using the standard Knoop hardness technique (100 g load), were carried out on a Tukon tester. This method was resorted to when it was found that samples were sufficiently brittle, often to break when macrohardness testing, using the Rockwell B-scale, was performed. However, as properties improved in the course of the work, more Rockwell B testing was possible, and this has been adopted as the standard method.

The diametral method (Refs. 4, 5) was used to obtain the diametral tensile strength. In this test, a cylindrical specimen of the Pyrrone, as produced, was loaded across the diameter in a special test rig using an Instron Universal Tester. The diametral tensile strength, normal to the ioaded diameter, is defined by the equation $\delta=2 P / \pi d t$ where $P$ is the applied load (pounds), $d$ is the diameter (inches), and $t$ is the thickness or cylinder height (inches!. The diametral method gives lower results than, for example, regular 3 point bend tensile testing. To take account of this, values have been doubled (Ref. 5) to correspond more nearly with the values that would be attainable in bend testing. Thermogravimetric analyses were conducted in air and nitrogen using a du Pont 950 Thermogravimetric Analyzer.

Measurements of the ultrasonic modulus were performed on a Sperry Rand UM715 U7trasound Reflectoscope, using both transmission and reflection methods. The transit time resolution for ultrasound pulses on the reflectoscope is around $1 \mu \mathrm{sec}$. Since the transit time, typical of the samples, is of the order of several $\mu \mathrm{sec}$, we have considerably improved the resolution by taking the output from the Reflectoscope to a Tektronix oscilloscope. The time scale on the oscilloscope is $0.01 \mu \mathrm{s}$ enabling the measurement to be made to an accuracy of $1 \%$. The elastic modulus $E$ is defined by the equation $V=\sqrt{E / \rho}$ where $V$ is the velocity of ultrasound propagation and $\rho$, the sample

density. The measurements, checked against the calibration standards, were usually made at 2.5 or $10 \mathrm{MHz}$. 


\section{RESULTS AND DISCUSSION}

\subsection{Thermogravimetric Analysis (TGA) of Starting Materials}

On finding that there were significant differences in the molding properties of powders mixed by various methods, the thermal behavior of these powders was studied by TGA. Figure 3 illustrates the rate loss with temperature at $5^{\circ} \mathrm{C} / \mathrm{min}$. in nitrogen of the PMDA-DAB mixtures made in the indicated fashion. The effects of poor mixing in the ballmilled mixture is immediately apparent. The theoretical percentage weight loss is $23 \%$, corresponding to 6 molecules of water. It is seen that the ballmilled mixture loses considerably more than this. At the temperature usually used as the top temperature in molding, i.e. $450^{\circ} \mathrm{C}$, the mixture was still losing weight. We suspect that this more than theoretical loss of weight reflects incomplete mixing of the monomers on a molecular level, thereby yielding incomplete polymerization and unreacted end groups which facilitate decomposition to volatile products. The blended mixture, as expected, polymerizes more fully, losing less weight than the ballmilled mixture but nevertheless still losing more than the theoretical amount at $450^{\circ} \mathrm{C}$.

Amorphous 1:1 salt adducts analyzed better (Figure 3 ); water was lost at lower temperatures in the initial stages indicating that more intimate mixing of the two types of monomer molecules facilitated earlier polymerization below $400^{\circ} \mathrm{C}$. The flattening of the curve between 400 and $500^{\circ} \mathrm{C}$ indicates that more complete polymerization occurred under nitrogen with no further degradation of the polymer. For this material, the initial choice of $450^{\circ} \mathrm{C}$ as the top molding temperature appears to have been fortunate. The amorphous nature of this 1:1 adduct was confirmed by $x$-ray diffraction.

Towards the end of the program an orange salt was prepared, crystalline as confirmed by powder x-ray diffraction methods. It would be expected that the molecules are most highly ordered in the crystalline salt. The TGA (Figure 4) shows a total weight loss up to $500^{\circ} \mathrm{C}$ which is very close to the theoretical value while the curve is relatively flat from $400-500^{\circ} \mathrm{C}$. Again, using $450^{\circ} \mathrm{C}$ as the top molding temperature appears to have been a good choice. Since in the molding process water is removed under more restricted conditions than under open TGA conditions with a small amount of material, it is reasonable to expect water removal to occur at a slightly higher temperature in molding than indicated by TGA. In a few cases where higher top molding temperatures were used, poorer physical properties resulted, although this was not checked exhaustively due to time limitations.

\subsection{Molding Performance}

\subsubsection{Molding Behavior of Unpurified PMDA-DAB}

Figure 5 illustrates a typical shrinkage temperature time sequence of PMDA-DAB ballmilled and heated at $3.8^{\circ} \mathrm{C} / \mathrm{min}$. at $4000 \mathrm{psi}$. Several regions of rapid shrinkage can be observed. The shrinkage regions at around $100^{\circ} \mathrm{C}$ and $250^{\circ} \mathrm{C}$ correspond to weight losses indicated by TGA. The intermediate rapid region at $150^{\circ} \mathrm{C}$ may coincide with the lowered melting point of $D A B$, normally $175^{\circ} \mathrm{C}$. The region at about $250^{\circ} \mathrm{C}$ could also correspond with the lowered melting point of PMDA, normally $275^{\circ} \mathrm{C}$. 




FIGURE 3. THERMOGRAVIMETRIC $\left(5^{\circ} \mathrm{C} / \mathrm{min}, \mathrm{N}_{2}\right)$ ANALYSIS OF THREE $1: 1$ PMDA-DAB COMPOSITIONS INCLUDING THE AMORPHOUS SALT (PMA-DAB) 


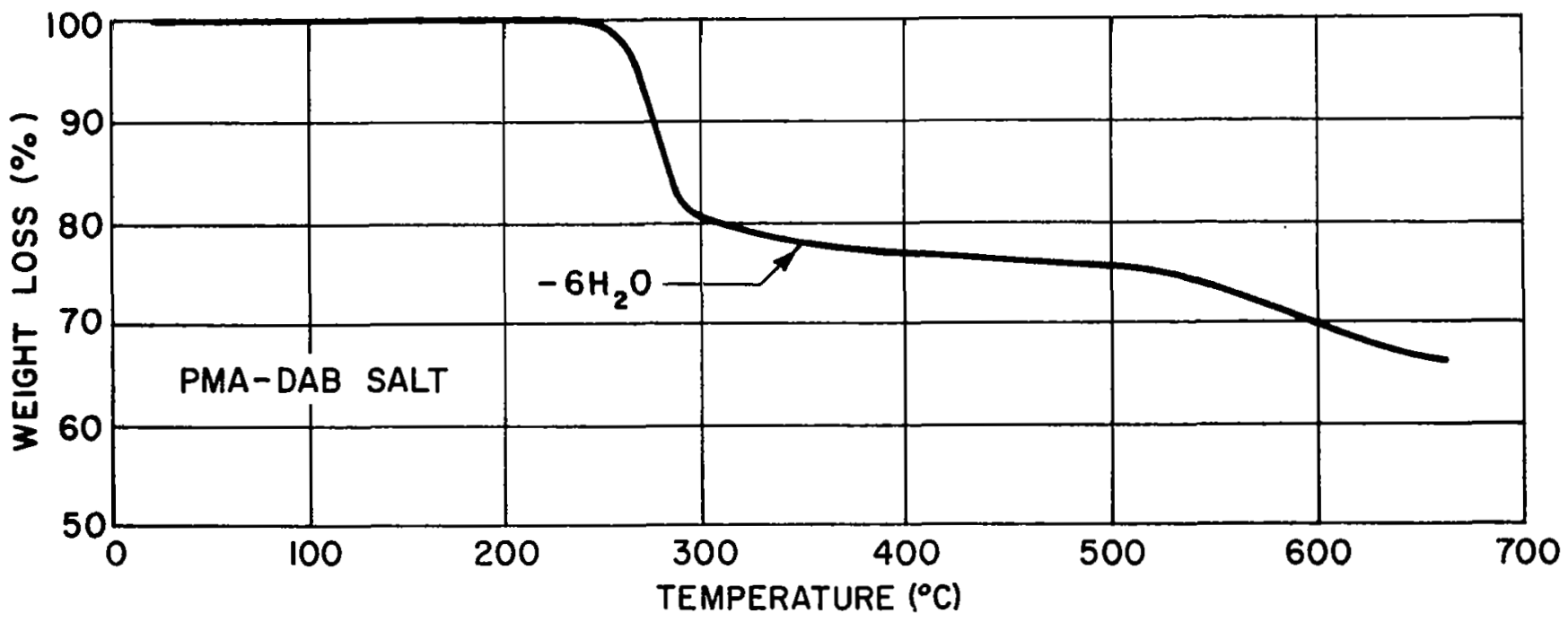

FIgURE 4. T.G.A. $\left(5^{\circ} \mathrm{C} / \mathrm{min}, \mathrm{N}_{2}\right)$ OF ORANGE CRYSTALLINE, PMA-DAB, SALT 


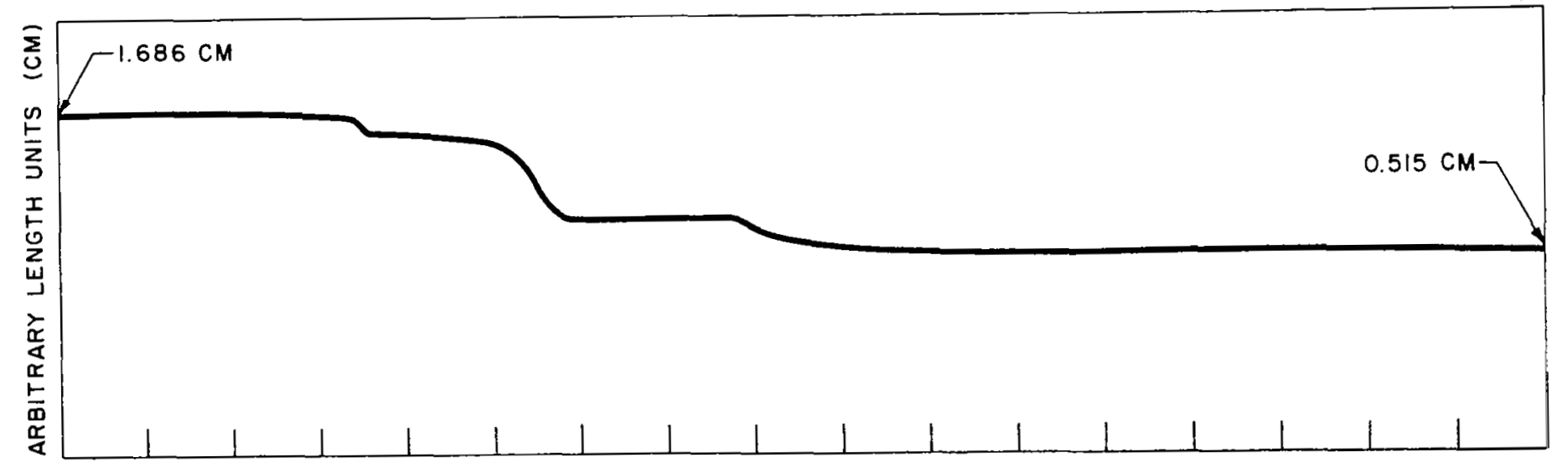

$\vec{N}$



FIGURE 5. TYPICAL SHRINKAGE BEHAVIOR OF MILLED PMDA-DAB AT CONSTANT PRESSURE 
The possibility that gases might be trapped during the rapid periods of shrinkage, led us to the development of the "1inear shrinkage method" which is illustrated in Figure 6 . However, the mechanical properties and the TGA results obtained on moldings by the linear method indicate that this fear was unfounded as discussed later. The linear method was subsequently used only on new mixtures or materials to pre-establish rough temperature pressure parameters for satisfactory molding.

In order to proceed toward the optimization of the molding process a data chart, illustrated in Fig. 7, was updated daily as results were obtained. Both rates of rise of temperature and applied constant pressure were varied within the bounds indicated as final densities were plotted to detect an optimum between rate of temperature rise and applied pressure, for the highest density, assuming that the highest density was desirable. A complex interaction between the two parameters was observed. Because polymerization and molding are occurring simultaneously, the control of both pressure (primarily affecting densification) and rate of temperature rise (primarily affecting the rate of polymerization) is very important. Too high a pressure or too high a rise in temperature causes the material to squeeze out of the die cavity, whereas the opposite conditions cause insufficient densification. The optimum conditions appear to allow the polymerization to proceed fairly rapidly, possibly with incipient melting of monomers or low oligomers plasticizing the mixture for densification.

Under the best molding conditions illustrated in Fig. 7, densities as high as $1.27 \mathrm{gms} / \mathrm{cc}$ were obtained in samples from ballmilied mixtures. In addition, as indicated by the filled circles, high strength and modulus values were obtained from most of the dense specimens; lower density specimens were variously cracked or delaminated, had open porosity or other internal defects and poor, if any strength. However, the best molding region was somewhat indistinct and the samples, which were mottled in appearance, having different hardnesses, as indicated later, in the different colored areas, indicated that much more intimate mixing was desirable.

Using blended mixtures, it was immediately apparent that polymerization was occurring more rapidly and uniformly. The optimum molding conditions are illustrated in Fig. 8. The range of temperature required was as before but, as expected, the pressure required was somewhat higher. The more intimate mixture polymerizes more rapidly, therefore, more pressure must be applied to densify the intractable polymer as it forms. A larger good molding region is observed. However, cracked specimens occurred within the best molding region. As before, the highest density specimens, up to 1.28 gms/cc., usually corresponded to good strength and modulus.

Proceeding to yet more intimate mixtures, freeze-dried preparations were molded. It was immediately apparent, however, from the densification behavior and subsequent TGA analysis that these moldings were very poor, presumably due to entrapped solvent materials. Thus, this approach was dropped quickly, particularly since the preparation of freeze-dried mixtures was tedious and time-consuming. 


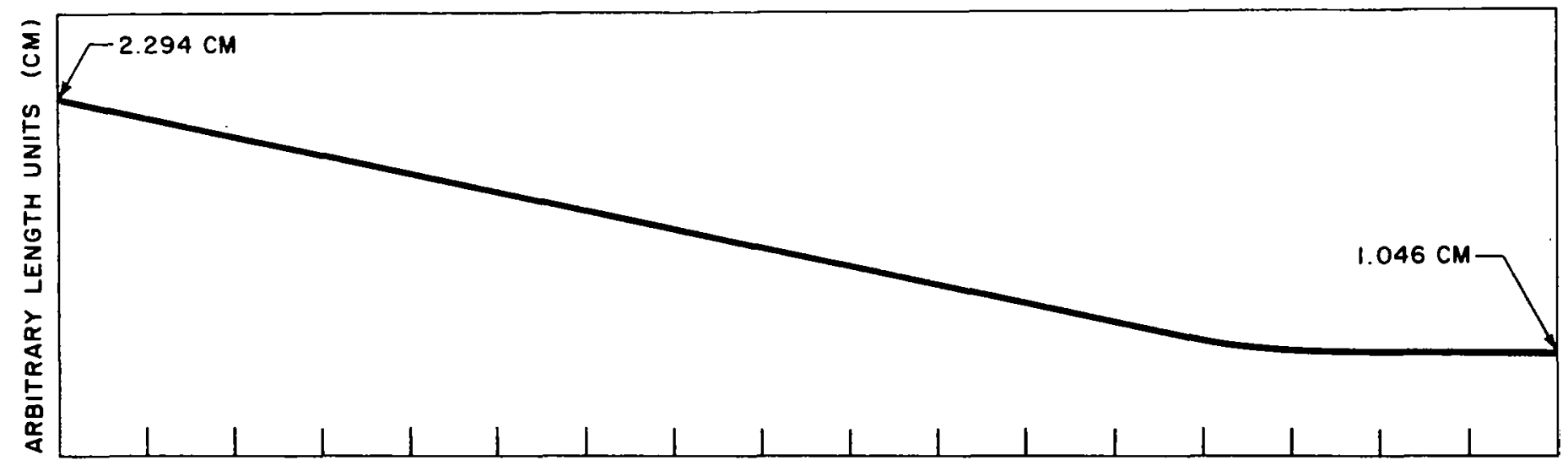

$\vec{A}$

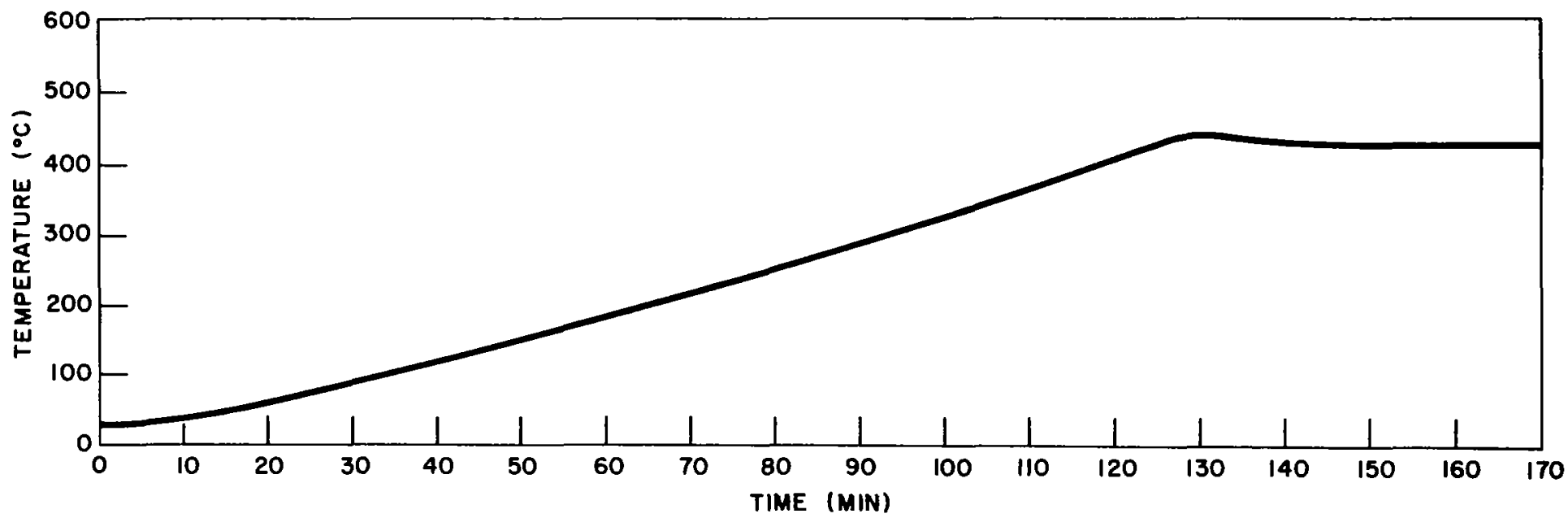

FIGURE 6. SHRINKAGE WHEN CONTROLLED BY THE "LINEAR SHRINKAGE" METHOD 


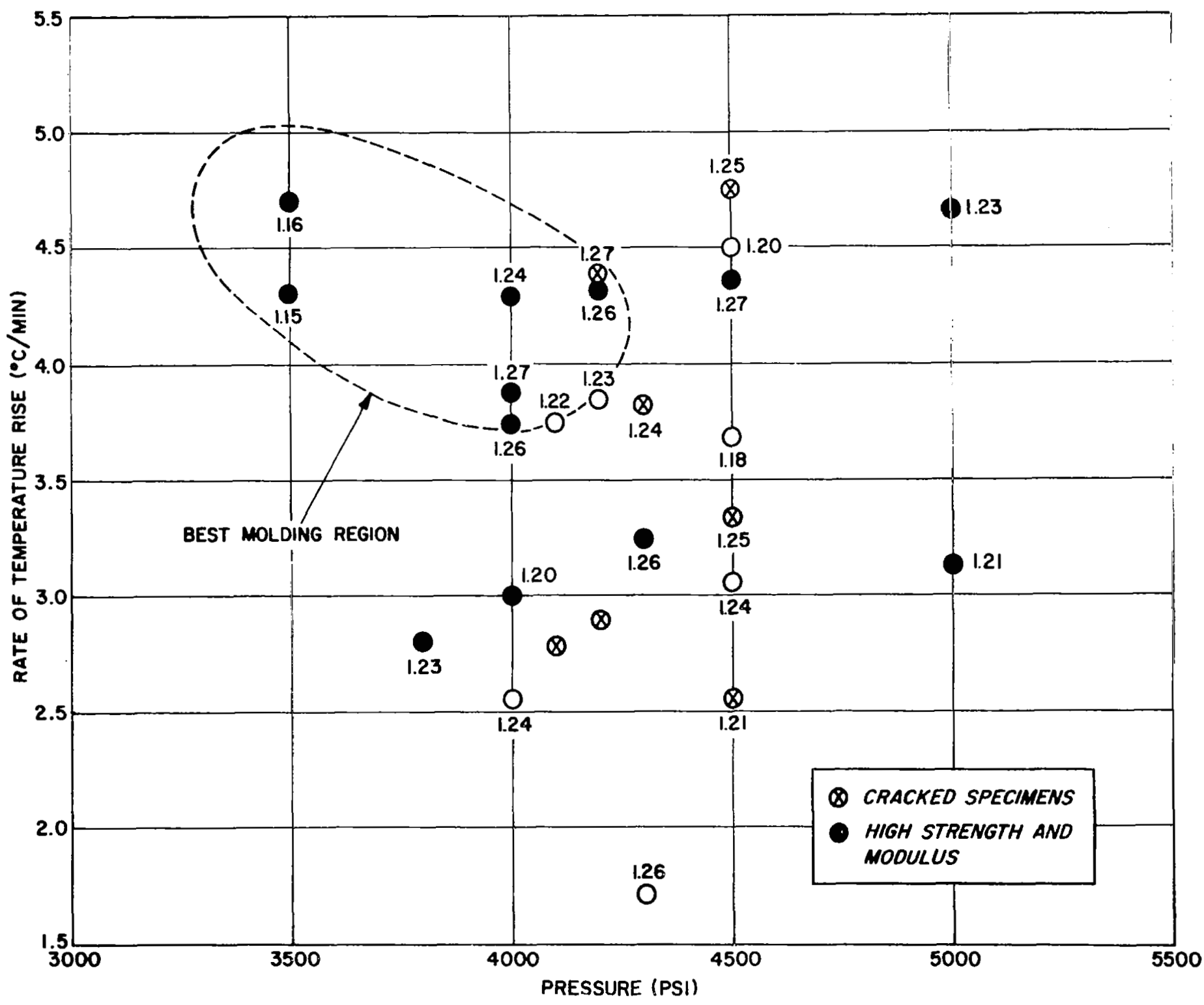

FIGURE 7. DENSITIES ACHIEVED IN SAMPLES FROM MILLED PMDA-DAB AS A FUNCTION OF APPLIED CONSTANT PRESSURE AND RATE OF RISE OF TEMPERATURE (UP TO $450^{\circ} \mathrm{C}$-HELD FOR 1 HR). BEST MOLDING REGION ILLUSTRATED. 


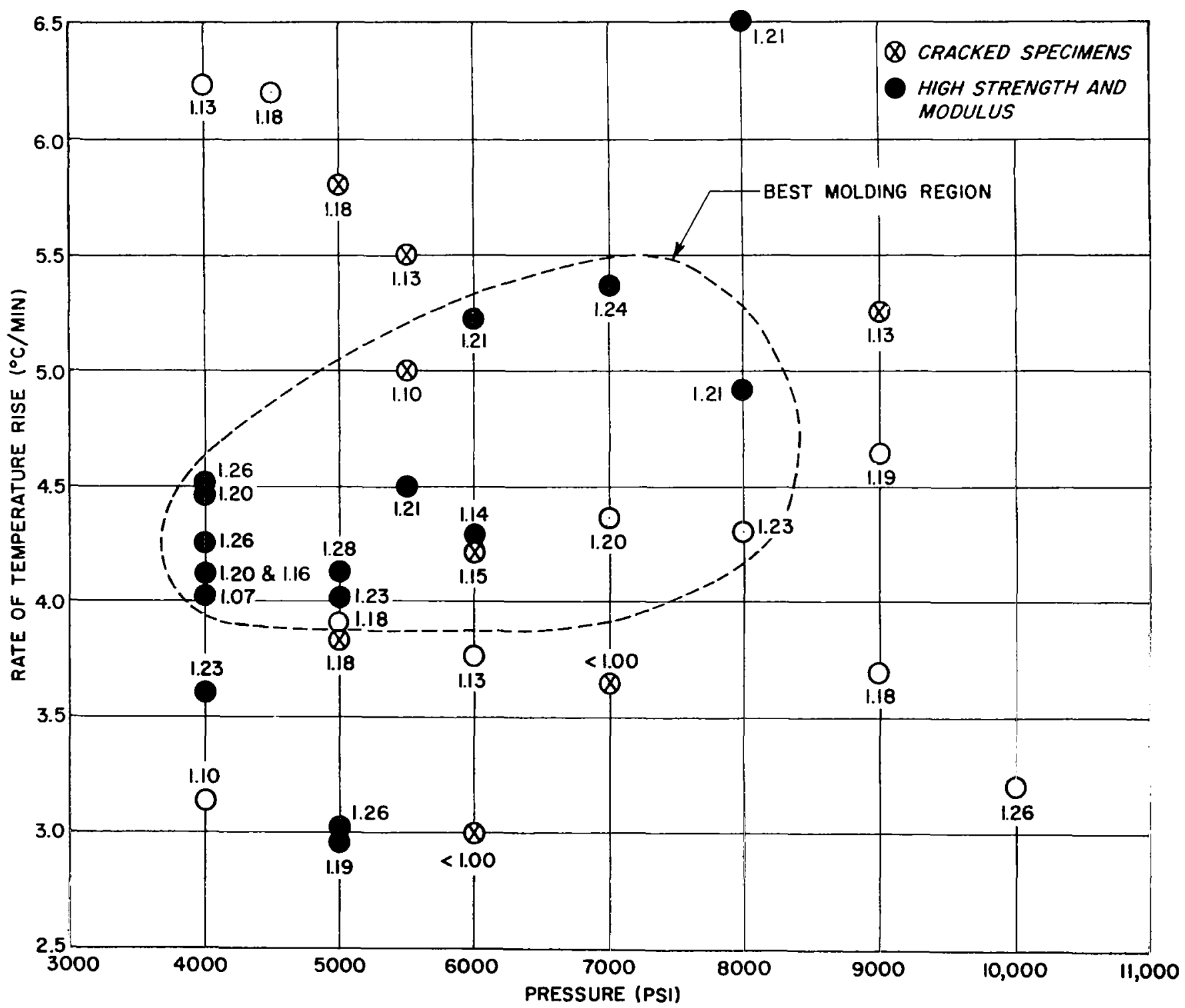

FIGURE 8. DENSITIES ACHIEVED IN SAMPLES FROM BLENDED PMDA-DAB AS A FUNCTION OF APPLIED CONSTANT PRESSURE AND RATE OF RISE OF TEMPERATURE (UP TO $450^{\circ} \mathrm{C}-H E L D$ FOR I HR). BEST MOLOING REGION ILLUSTRATED. 
It was then found that intimate monomer mixtures could be made easily in the form of a 1:1 salt of DAB and hydrolyzed PMDA which readily precipitated on mixing hot solutions of each monomer. The first amorphous precipitates were extremely difficult to dry, requiring several weeks in vacuum to drive off methanol. The molding behavior, however, was soon found to be very promising as shown in Figure 9. The molded specimens appeared very uniform, and most importantly the TGA, detailed later, showed a superior thermal stability in air. Microhardness results, randomly taken over the specimen, also were much more uniform than from moldings derived from either the milled or blended mixtures. For top densities, about the same as before, higher rates of rise of temperature compensated for slightly lower pressures used than in the blended case. This is more economical as the total time required per sample is greatly reduced.

The effect upon the shape of the shrinkage curve of going from milled to blended to salt mixtures was to smooth out the shape of the shrinkage curve so that the sharp periods of shrinkage were greatly reduced. This was also very encouraging, reducing the possibility of a need for the linear approach. But other molding problems began to appear. After the results shown in Figure 9 were completed another batch of the amorphous $7: 1$ salt was prepared for the molding of 15 samples to be supplied to NASA/Langley as per the contract requirement. The elemental analysis of the second batch was identical to the first and the T.G.A. results on the powders were also the same. Nevertheless, in attempting to mold good specimens at about $6.5^{\circ} \mathrm{C} / \mathrm{min}$ and 4000 psi, the best region in Figure 9 , only poor results were obtained as shown in Figure 10. It was necessary, Figure 10, to find a new region of best molding for this new batch as depicted. Moreover, densities achieved in this case were much higher as can be seen and other good features as given in Table II were apparent. We are not sure that the conditions for the second amorphous salt batch are optimized but time and money did not allow for further searching. It should be pointed out that the first batch of amorphous salt might also mold well under these new conditions because the data of Figure 9 does not spread into the same pressure/rate of temperature rise region.

In spite of these difficulties, five of the samples delivered to NASA were made, in the middle of the best molding region as in Figure 10, from the second amorphous salt batch as indicated in Table IV. At this point the material ran out and we were forced to consider making yet another batch. In checking the preparation in detail it was noticed that an orange crystalline material could be prepared which also turned out to be a 1:1 salt, containing less of the same colored impurities as indicated by visible absorption spectra (presumably amine oxidation products) than the amorphous salts. The TGA of the material, shown in Figure 4 , also indicated it may be a better, more reproducible molding material. We had noticed this product earlier but were misled by what turned out to be faulty elemental analyses. Close investigation revealed that the orange material also gave a correct analysis for a 1:1 salt adduct.

These orange crystals had several other desirable features for molding. First of a11, the measured "green density" of the crystalline material, $1.38 \mathrm{~g} / \mathrm{cc}$, was much higher than that of the amorphous salt so that shrinkage to the final state was much reduced. In further optimization, crystalline salts should facilitate faster molding cycles.

Again, no optimization of molding was possible but as indicated in Table IV the remaining 9 specimens supplied to NASA were made under conditions 




FIGURE 9. DENSITIES ACHIEVED IN SAMPLES FROM FIRST BATCH OF AMORPHOUS PMA-DAB "SALT" AS A FUNCTION OF APPLIED CONSTANT PRESSURE AND RATE OF RISE OF TEMPERATURE (UP TO $450^{\circ} \mathrm{C}$-HELD FOR I HR). BEST MOLDING REGION ILLUSTRATED. 


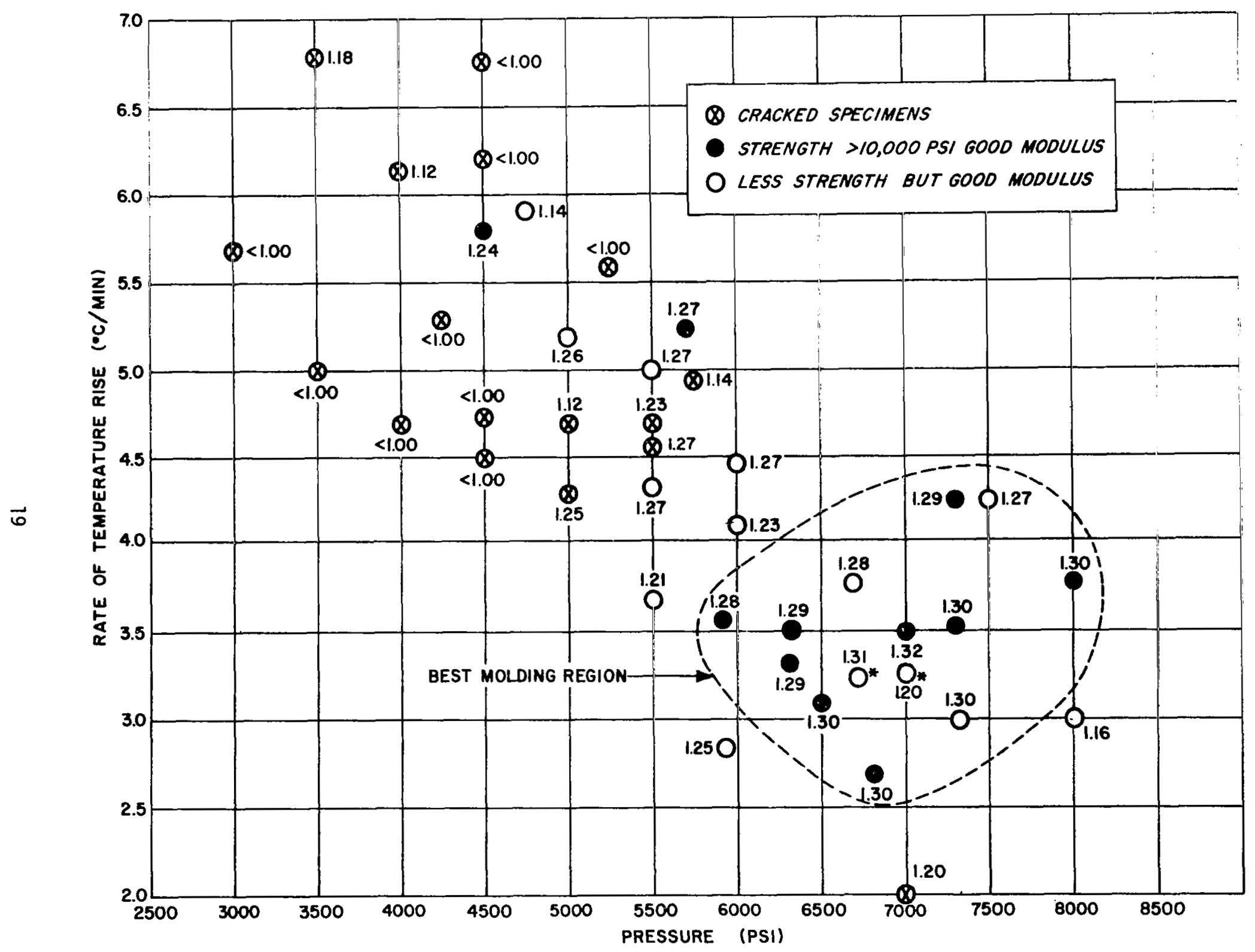

FIGURE 10. DENSITIES ACHIEVED IN SAMPLES FROM SECOND BATCH. OF AMDPHHOUS PMA-DAB "SALT" AS A FUNCTION OF APPLIED CONSTANT PRESSURE AND RATE OF RISE OF TEMPERATURE (UP TO $450^{\circ} \mathrm{C}$-HELD FOR 1 HR). BEST MOLDING REGION ILLUSTKATED.

(NOTICE DIFFERENT CONDITIONS FROM FIG. 9) \$SUPPLIED TO NASA 
similar to those of the amorphous salt supplied. About fifteen preliminary runs were necessary with the orange salt to find that the conditions used on those supplied were satisfactory (though again not optimized). As might be expected from the tightly bonded structure of the orange salt (high green density, etc.) and the rapid polymerization rate at $250-300^{\circ} \mathrm{C}$ (Figure 4 ), higher pressure is necessary, 7,500 psi and faster rates of rise of temperature $4.5^{\circ} \mathrm{C} / \mathrm{min}$. Densities of the same order as attained with the amorphous salt were achieved, Table IV. Because the material is crystalline, it can be expected that pregrinding would affect the molding properties, and this also was not considered. It was seen earlier (Figure 9) that samples showing very even sinrinkage gave the best results. Specimens which had undergone rapid or unusually great shrinkage did not have good strength or modulus properties. In the case of the highly crystalline orange material, however, virtually all samples exhibited a desirable slow uniform shrinkage behavior as depicted in Figure 11. The period of maximum shrinkage occurred around $250^{\circ} \mathrm{C}$ which agrees with the onset of rapid polymerization as depicted in Figure 4 . As will be apparent later, the properties of samples molded in this manner from this kind of sali were in every way superior to specimens made from milled, blended, or amorphous salt material. It was also found that the preparation of the orange crystalline salt is facilitated by "seeding". We strongly recomend the use of crystalline salts in further molding studies.

It should also be noted that the pressure ranges in this work are comparable to those used in other molding studies where prepolymers or oligomers are utilized.

\subsubsection{Molding Behavior of Purified Grades of PMDA-DAB}

Although good results could be obtained with commercial monomers, it was, nevertheless, of some interest to see if purified materials would give better results. For a blended pure PMDA-pure DAB mix, it was readily apparent that polymerization was much slower than for the impure grade, resulting in the need for lower pressure or slower rates of rise of temperature to prevent squeezing the much more fluid mix from the die. These conditions are less desirable.

To follow up, we briefly examined product densities as a function of monomer purity with the following blended mixes molded arbitrarily at $4000 \mathrm{psi}$ and about $4.0^{\circ} \mathrm{C} / \mathrm{min}$.

$\begin{array}{ll}\text { Pure PMDA and pure DAB } & 1.26 \mathrm{~g} / \mathrm{Cc} \\ \text { Pure PMDA and impure DAB } & 1.23 \mathrm{~g} / \mathrm{CC} \\ \text { Impure PMDA and pure DAB } & 1.16 \mathrm{~g} / \mathrm{cc} \\ \text { Impure PMDA and impure DAB } & 1.07 \mathrm{~g} / \mathrm{cc}\end{array}$



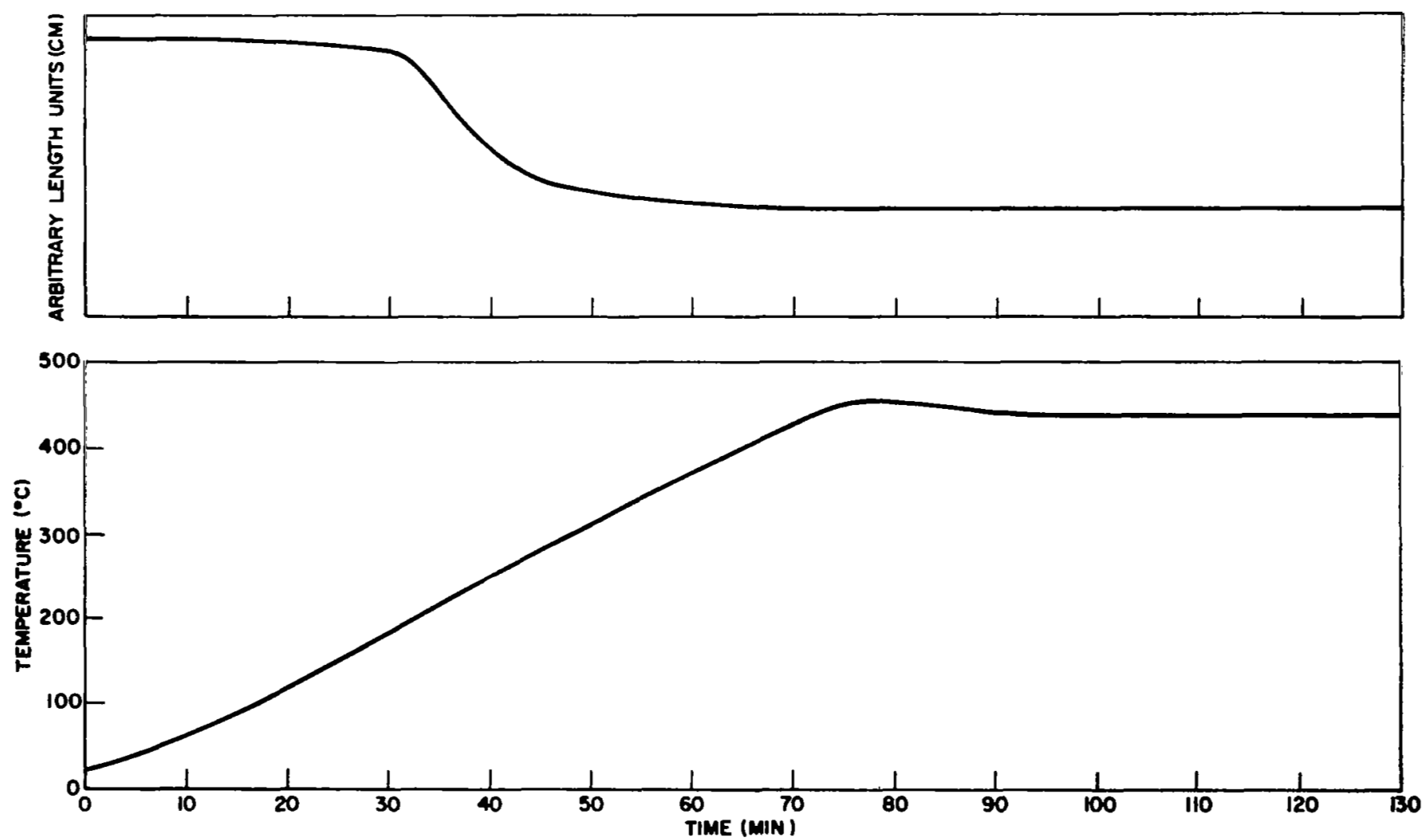

FIGURE 11. TYPICAL SHRINKAGE BEHAVIOR OF ORANGE CRYSTALLINE $1: 1$ SALT OF PMA-DAB AT CONSTANT PRESSURE 
Since a lower density reflects faster polymerization, these results indicate that impurities catalyze polymerization. The conditions were not optimal for each mix, but the mixes were prepared to minimize the interference of purely physical effects such as particle size, etc. It is clear that both the commercial grades of DAB and PMDA have contaminants which promote polymerization. In case of PMDA, this is almost certainly the free acid form and this is consistent with previous reports of acid catalysis of polymerization and cyclization in the formation of polyheterocyclics (Refs. 6,7,8) such as using polyphosphoric acid as a solvent and catalyst or organosulfonic acids as catalytic additives (Ref. 9). In the case of DAB, we suspect that protons are yielded on conversion of the 1-electron oxidation product, the socalled Wurster ion of the amine, to quinoid products. In the purified BTDADAB system the same effect was even more dramatic as indicated later in this report.

The need to study effects of purity was greatly reduced when the 1:1 salts were discovered. Purification was achieved during the preparation, as indicated by good analyses. Moreover, PMDA is present as the free acid, obviating the need for acidic impurities or added catalysts. Fastest polymerization was observed with crystalline salts, presumably because of optimum molecular mixing and alignment of the monomers. Also, even though the polymerization is faster with crystalline salts, attaining fully densified moldings is easier because the green crystalline salt density is already $1.38 \mathrm{~g} / \mathrm{cc}$.

\subsubsection{Molding Using the Linear Shrinkage Method}

The linear shrinkage was used most for blended PMDA-DAB. Compared to using ballmilled monomer mixtures, much greater reproducibility in density from $1.10-1.25 \mathrm{~g} / \mathrm{cc}$ was achieved with wide variation of the rate of rise of temperature from $3-7^{\circ} \mathrm{C} / \mathrm{min}$. The pressure variations compensated for the differing plasticity relationships with temperature. The mechanical properties etc. did not appear to favor this method for this mix in spite of the better reproducibility. However, it may well be that the recently uncovered.salts might show improvements by this approach in further work.

\subsection{T.G.A. Results on Moldings}

Of most interest is the thermal stability of moldings in air although some data in nitrogen has also been obtained. Thermal stability of materials in air are commonly measured at up to $10^{\circ} \mathrm{C} / \mathrm{min}$ for example as reported in the literature. However, such results bear no absolute relation to useful applications where materials are going to be held at elevated temperatures for long periods of time. Figure 12, for example, shows a representative TGA curve for a PMDA-DAB molding from the milled mixture with the highest tensile strength found, $21,000 \mathrm{psi}$. The upper curve at $10^{\circ} \mathrm{C} / \mathrm{min}$. suggests a themal stability (i.e. no weight loss) to about $500^{\circ} \mathrm{C}$ for this material. A more realistic value, however, is obtained by measuring the TGA at $0.5^{\circ} \mathrm{C} / \mathrm{min}$. as shown in the lower curve with weight loss commencing at a little more than $300^{\circ} \mathrm{C}$. With slow rates of rise of temperature, we were able to discriminate fairly easily between small differences in molded samples; whereas, with the fast rate of heating, most products appeared stable to near $500^{\circ} \mathrm{C}$. We would recommend that future non-isothermal work on the stability of high temperature plastics be carried out at no more than $0.5^{\circ} \mathrm{C} / \mathrm{min}$; all TGA data on the moldings in this report are based upon this rate. 




FIGURE 12. T.G.A. OF A MOLDING FROM MILLED PMDA-DAB DONE IN AIR AT $10^{\circ} \mathrm{C} / \mathrm{min}$ and $0.5^{\circ} \mathrm{C} / \mathrm{min}$ SHOWING NEED FOR SLOWER RATE FOR MEANINGFUL INTERPRETATION. 
The progressive improvement in thermal stability, as the molding techniques improved and methods of mixing became more intimate, is shown in Figure 13, with an enlarged view in Figure 14. For a given method of mixing, thermal stability generaliy improved as the density increased, and Figure 13 shows results that were typical of the best for each particular method. Moldings made from milled PMDA-DAB showed thermal stability generally up to about $330^{\circ} \mathrm{C}$. Blended samples, as indicated, using both the constant pressure and linear methods showed stabilities to around $350-370^{\circ} \mathrm{C}$. The best stability is shown, however, by the moldings made from the 1:1 crystalline PMDA-DAB salt with stabilities to $400^{\circ} \mathrm{C}$; the improvement doubtless is related to more perfect polymerization to the more nearly theoretical Pyrrone structure, a view reinforced by exceptionally good agreement of elemental analysis results with theory. With milled and blended materials the thermal stability was very irreproducible, but with the salt materials made under the optimum conditions, as indicated earlier, the TGA analys is was extremely reproducible at around $400^{\circ} \mathrm{C}$.

A brief investigation was made of the effect of the top molding temperature on the thermal stability of moldings made with the crystalline salt. For three samples, molded identically, except that the samples were held for one hour at $450^{\circ} \mathrm{C}, 500^{\circ} \mathrm{C}$ and $540^{\circ} \mathrm{C}$, the air stability was $400^{\circ}, 380^{\circ} \mathrm{C}$ and $360^{\circ} \mathrm{C}$ respectively as indicated by TGA. We are reasonably certain that $450^{\circ} \mathrm{C}$ is about the optimum top temperature for our forming conditions, both from this evidence and from the pre-evaluation as shown in Figure 4. Similar effects were indicated in our work on milled and blended PMDA-DAB. Similarly AVCO workers have found that $400^{\circ}-425^{\circ} \mathrm{C}$ is a good forming temperature when using 01 igomers instead of monomers. (Ref. 10)

Specific TGA stability temperatures for various samples are indicated in the Summary Tables at the end of this report.

\subsection{UT trasonic Modulus Results}

Increasingly good, reproducibly high ultrasonic modulus values were achieved as work progressed. In many early specimens it was not possible to measure modulus at all because of internal flaws. The range of modulus measured with each type of mixing is as follows:

$\begin{array}{ll}\text { Milled } & 1.7-2.8 \times 10^{6} \mathrm{psi} \\ \text { Blended } & 1.0-2.8 \times 10^{6} \mathrm{ps} i \\ \text { Amorphous Salt } & 0.9-4.2 \times 10^{6} \mathrm{psi} \\ \text { Crystalline Salt } & 1.0-1.2 \times 10^{6} \mathrm{psi}\end{array}$

It can be seen that the higher values measured increased as the method of mixing improved reflecting much better internal bonding; while higher density reflected more perfect specimens. The lower bounds, decreasing in the same direction, are for lower density specimens for which no modulus values could be obtained from early moldings. The fact that results were obtained in later specimens again indicates uniform polymerization. 


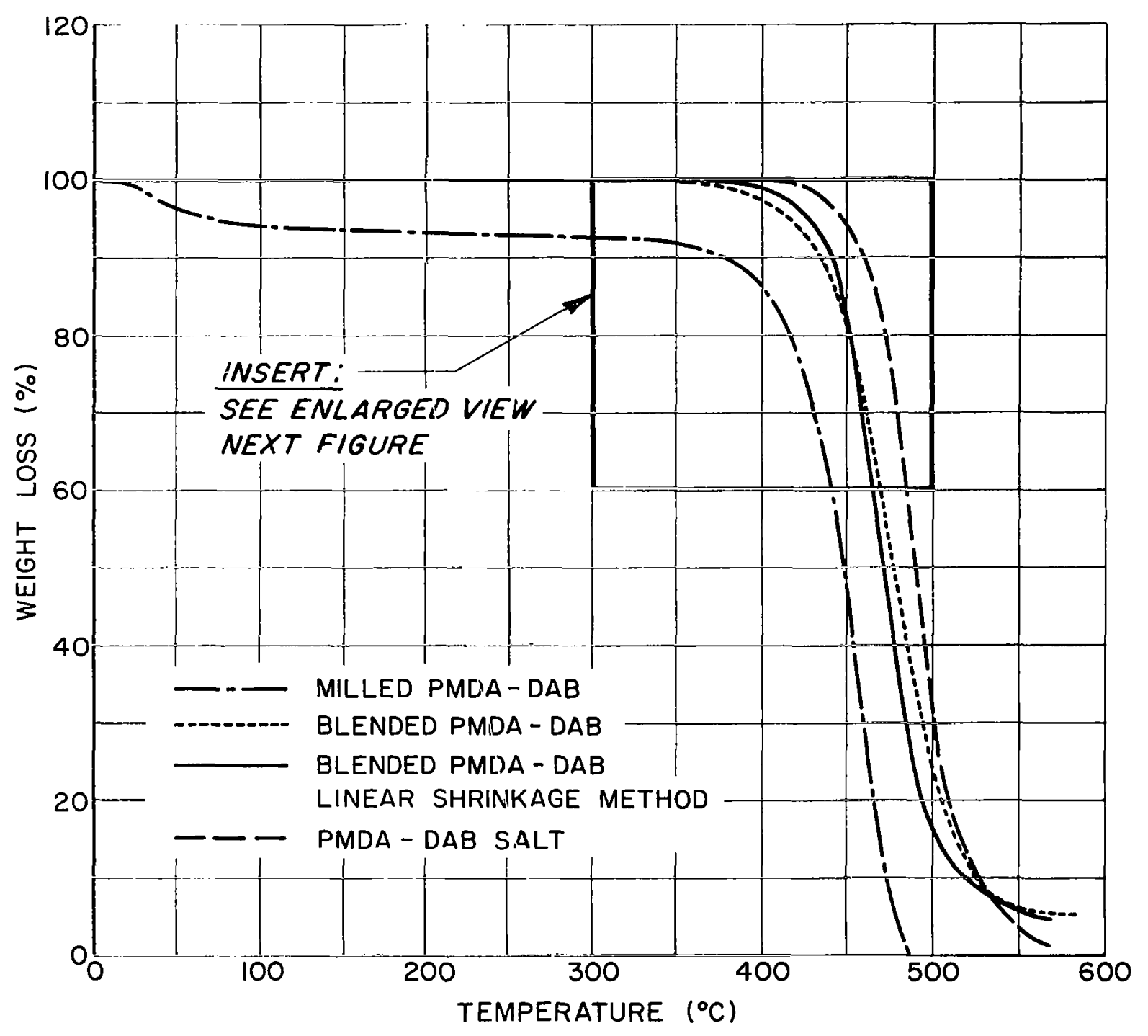

FIGURE 13. T.G.A.'S (AIR, $0.5^{\circ} \mathrm{C} / \mathrm{min}$ ) of VARIOUS MOLDINGS, MADE AS INDICATED, OF PMDA (or PMA)-DAB 


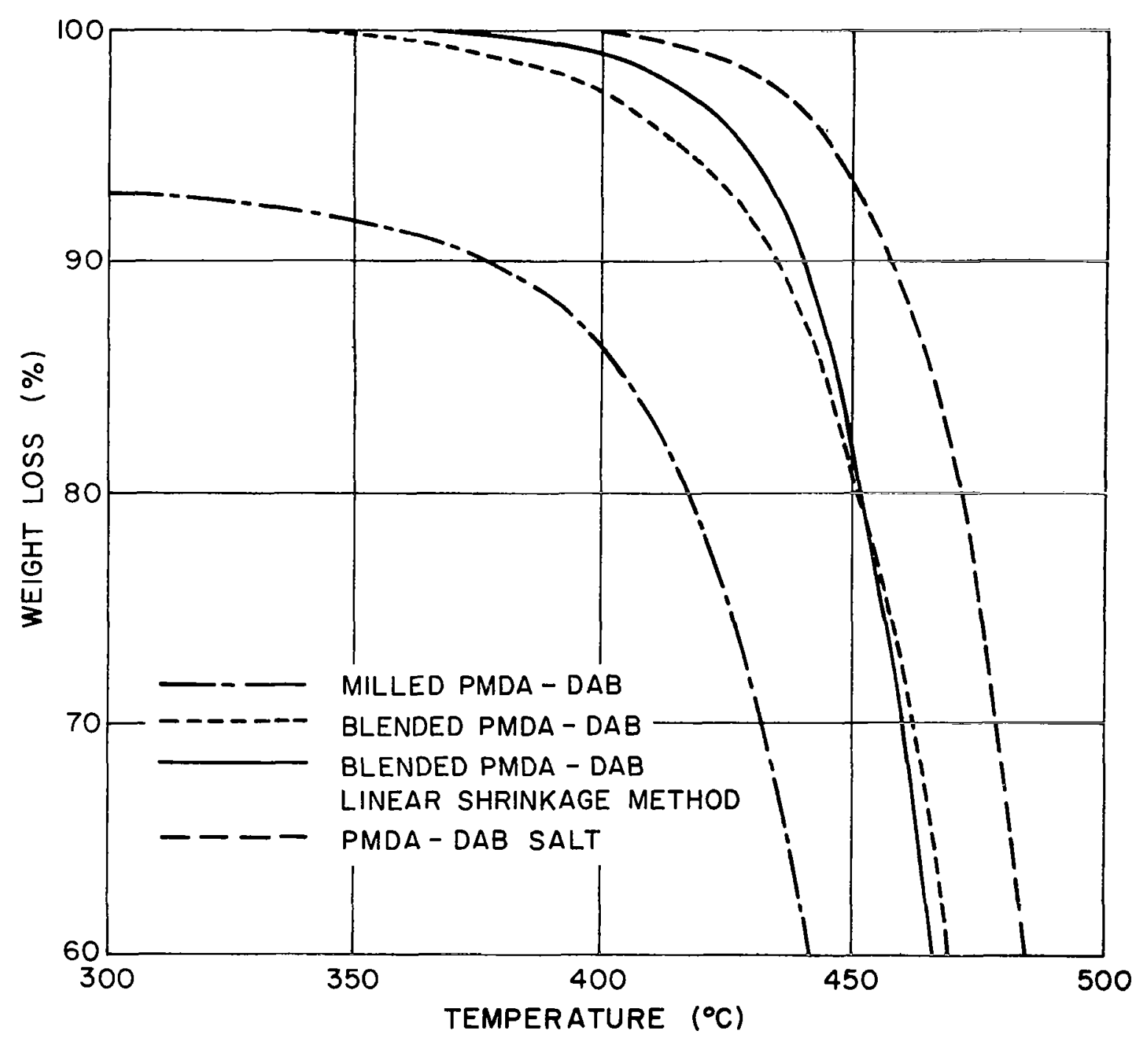

FIGURE 14. ENLARGED VIEW OF INSERT OF FIGURE 13 
In 211 cases, the very highest density specimens, which did not give the best strength values, also gave poor or no modulus measurements. The reproducibility of modulus values in the optimum molding region generally improved on going from milled to blended to salt materials, and were the best with moldings made from the orange crystalline salt; these values are given in the Summary Tables later for all of the 15 samples as supplied to NASA. The highest value for modulus, $1.2 \times 10^{6}$ psi, for a molding made from crystalline salt, is unusual and inexpiticable. Occasionally, in each molding sys tem a very high result was obtained. Modulus could be a sensitive function of the degree of cross-linking of these materials. Color changes that may be indicative of this are apparent even in moldings from the crystalline salt, where a bluish color was achieved with higher hardness and more brittleness (these often broke in macrohardness testing), while a brownish cast was seen with softer materials. This whole area should be closely investigated in the future. For high density specimens of Pyrrone, $1.37 \mathrm{~g} / \mathrm{CC}$, AVCO workers (Ref. 10) were able to attain a static flexural modulus of about $0.9 \times 10^{6} \mathrm{psi}$, very similar to our later data.

\subsection{Hardness Results}

Progressively uniform hardness was achieved during the work period. Early samples made by milling showed great variation in hardness properties; particularly the hardness varied from dark brown colored regions where hardness was high and perhaps attributable to more crosslinking to lighter orange colored areas where the hardness was lower. The milled samples showed a large variation in hardness both within single specimens and as a function of density, The Knoop hardness ( $100 \mathrm{~g}$ load) rose in good specimens from about $35 \mathrm{~kg} .1 \mathrm{~mm}^{2}$ at a density of $1.15 \mathrm{~g} / \mathrm{cc}$ to the highest values around $60 \mathrm{~kg} . / \mathrm{mm}^{2}$ at a dens ity of about $1.23 \mathrm{~g} / \mathrm{cc}$; hardness then dropped again to about $30 \mathrm{~kg} . / \mathrm{mm}^{2}$ at a density of about $1.27 \mathrm{~g} / \mathrm{cc}$. A maximum in hardness versus density has been seen in all compositions. The better blended samples showed much less variation in hardness, both within single specimens and as a function of the density. The highest hardness values were, in this case, about $50 \mathrm{~kg} . / \mathrm{mm}^{2}$ at a density of about $1.23 \mathrm{~g} / \mathrm{cc}$. At low and high densities, about $1.18 \mathrm{gm} / \mathrm{cc}$ and above $1.25 \mathrm{~g} / \mathrm{cc}$, hardness values around $35 \mathrm{~kg} / \mathrm{mm}^{2}$ again were observed.

With specimens made from the amorphous salt, a very large variation in hardness ranging between 20 and $50 \mathrm{~kg} / \mathrm{mm}^{2}$ was seen with much less apparent density dependence. It was found that, hardness was roughly proportional to strength for samples that were strength tested. However, no close relationship between hardness and density or strength was unearthed and hardness cannot, as far as we can see at present, be used as a "quality control" parameter. This may be partly because microhardness tests too small a region of non-uniform Pyrrone moldings. However, in the Summary Table of the data on 15 salt derived specimens supplied to NASA, hardness was much more reproducible and, in these cases, macrohardness tests could be carried out on the less brittle samples. For moldings made from the orange crystalline salt it may be possible to use macrohardness as a control parameter and as a non-destructive test. 
It is interesting to note that these plastics appear to be the hardest unfilled plastics ever made. A value of 100 on the Rockwell E scale, commonly used for plastic materials, corresponds to 70 on the Rockwell B. The range of 70-100 Rockwell $B$ is typical of high temperature stainless steels and hardened titanium alloys. Special applications i.e. for bearings etc. may arise using this particular property of Pyrrones.

\subsection{Diametral Strength}

Diametral tensile strengths followed a similar pattern to the other physical properties measured. Increasing reproducibility was achieved, but sometimes at the expense of less high values. For example, the highest tensile strength found during the whole work period was 21,000 psi on a sample of milled PMDA-DAB; but this molding composition often also gave samples of very low density and strength. blended materials produced more reproducibility in strength but samples made both by the constant pressure and the linear shrinkage method generally reached strengths of only about 15,000 psi. Improvements were obtained with the amorphous salt starting material; the highest value achieved was 19,800 psi. For the type of samples sent to NASA the highest strength found was 11,500 psi (only two specimens could be tested because of lack of time), but offsetting this is much higher thermostability which is of paramount importance. Strength results are summarized in the Summary Tables of Properties. The increasing uniformity and reproducibility of strength results again reflects a better uniform, more linear polymer formation using the more sophisticated mixing techniques. Better reproducibility, even at the expense of slightly lower upper tensile strengths is clearly more desirable in any engineering application. For the later specimens, it was apparent that tensile strengths showed a good correspondence with the modulus, i.e., as the modulus increased so also did the tensile strength. Again, a non-destructive test may be available.

For each composition again, an optimum strength: density relationship was confirmed. The general quality of specimens of anomalously high density was poor. 


\section{GENERAL RESULTS AND DISCUSSION OF OTHER SYSTEMS}

Data for systems other than PMDA-DAB is included in the Summary Tables in Section 5. In no case was optimization possible. However, nothing was observed which conflicted with the general trends already outlined for the PMDA-DAB system and we would anticipate that rigorous procedures could produce much superior physical properties in all cases.

\subsection{Preevaluation of Molding Powders Other Than PMDA-DAB}

General conclusions drawn during the preevaluation of PMDA-DAB powders by TGA methods were found to apply equally well to other sys tems. Figure 15, for example, illustrates the different TGA behavior of BTDA-DAB as a milled mixture and as the 1:1 salt. Polymerization of the salt is completed at lower temperatures, around $400^{\circ} \mathrm{C}$, due to the molecular scale of mixing. The flat region between $400-500^{\circ} \mathrm{C}$ indicates that good thermally stable moldings would be obtained at $450^{\circ} \mathrm{C}$. The milled mixture still shows mass loss at this temperature and should not produce moldings with as good properties. Quite a few molding experiments were carried out on milled and blended mixtures before the salt was made.

Figure 16 illustrates the good TGA behavior of the purple crystalline NTCA-DAB salt. The theoretical weight loss occurs at $450^{\circ} \mathrm{C}$ with a stable flat region between $450^{\circ} \mathrm{C}$ and $550^{\circ} \mathrm{C}$. This TGA sugges ts that molding up to $500^{\circ} \mathrm{C}$ might produce better results. We had no time to investigate this further.

The TGA behavior of a molecule containing all the functional groups necessary for it alone to produce a high temperature polymer, namely, 4,5diaminonaphthalic anhydride (Ref. 11, 12) appears in Figure 17. A short decomposition region is seen between 300 and $425^{\circ} \mathrm{C}$ with theoretical weight loss at $450^{\circ} \mathrm{C}$. However, no flat region seems to be present for this particular monomer. A few samples have, however, been molded around $450^{\circ} \mathrm{C}$ with this material.

Figure 18 illustrates the only imide system that we have looked at. The TGA in both air and nitrogen at $5^{\circ} \mathrm{C} / \mathrm{min}$. is shown, and the choice of $450^{\circ} \mathrm{C}$ again as the top molding temperature appears appropriate. Even the finely divided polymer materiaT, as produced in the TGA apparatus, appears stable in air to $450^{\circ} \mathrm{C}$ with this rate of rise of temperature.

\subsection{Molding Results}

The parameters outlined for the molding of PMDA-DAB were found to apply in all the other systems that were studied. All salts gave much more regular uniform shrinkage than blended or milled materials and the extent of shrinkage was less due to the higher density of the starting material. When conducted properly, no problems due to water escape were observed, al though in the case where the $\mathrm{HCl}$ salt of TAB was used there were definite signs that $\mathrm{HCl}$ emission was causing problems. In the very small amount of work that was carried out on half ester materials of PMDA-DAB, problems due to the escape of methanol and isopropanol were indicated. These materials also tended to squeeze very easily from the die, and thus were very unsuitable for our molding operation. Summary tables of noteworthy specimens list the densities achieved under the various molding conditions. 


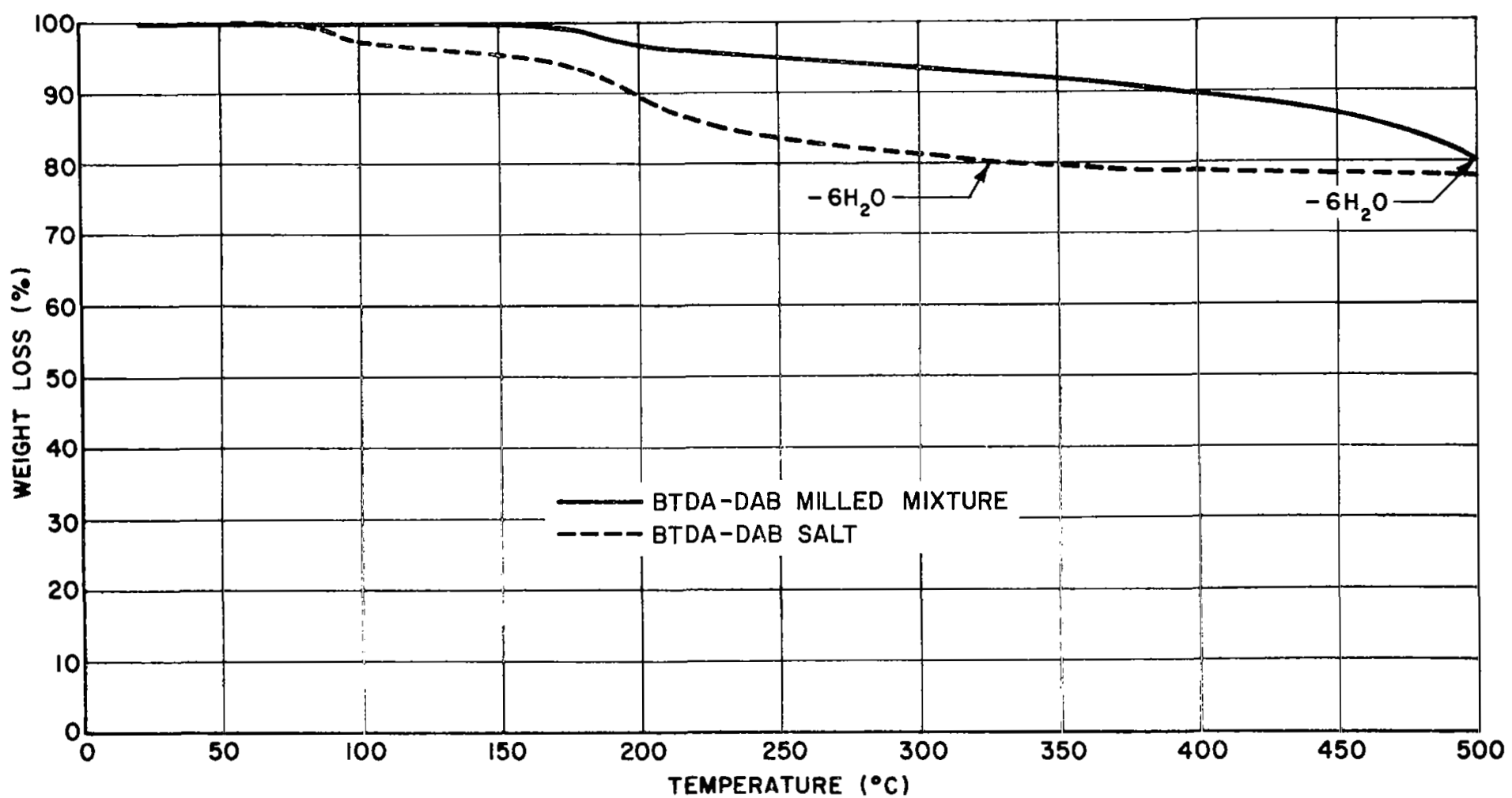

FIGURE 15. T.G.A. $\left(5^{\circ} \mathrm{C} / \mathrm{min}, \mathrm{N}_{2}\right)$ OF BTDA-DAB MOLDING COMPOSITIONS 


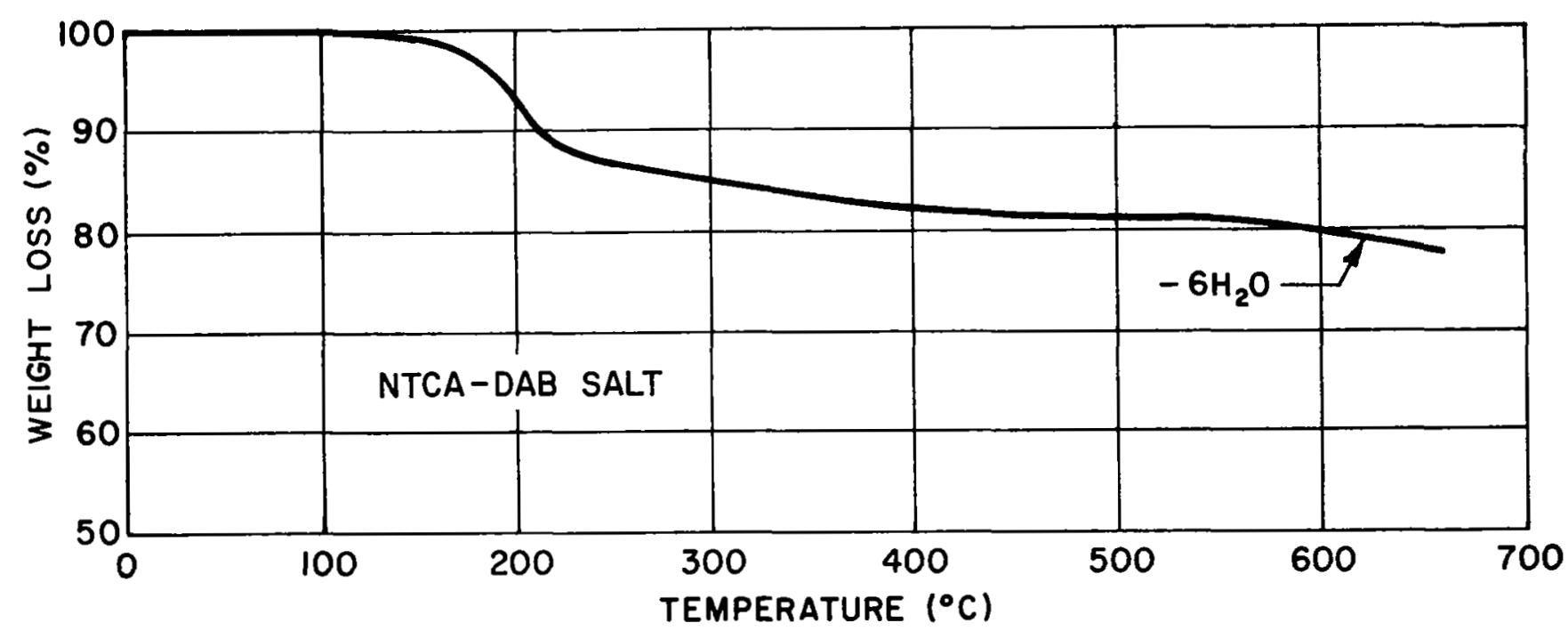

FIGURE 16. T.G.A. $\left(5^{\circ} \mathrm{C} / \mathrm{min}, \mathrm{N}_{2}\right)$ OF PURPLE CRYSTALLINE SALT OF NTCA-DAB

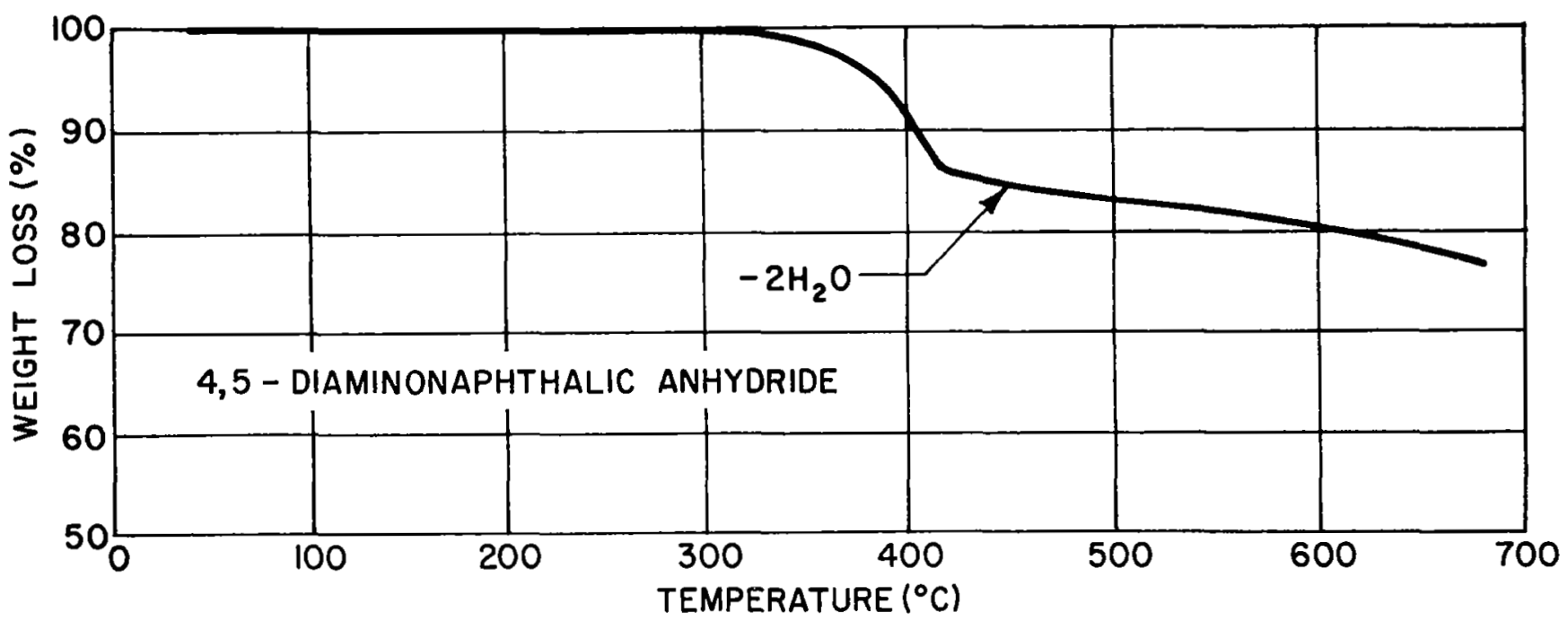

FIGURE 17. T.G.A. $\left(5^{\circ} \mathrm{C} / \mathrm{min}, \mathrm{N}_{2}\right)$ OF OLIVE GREEN CRYSTALLINE DANA 


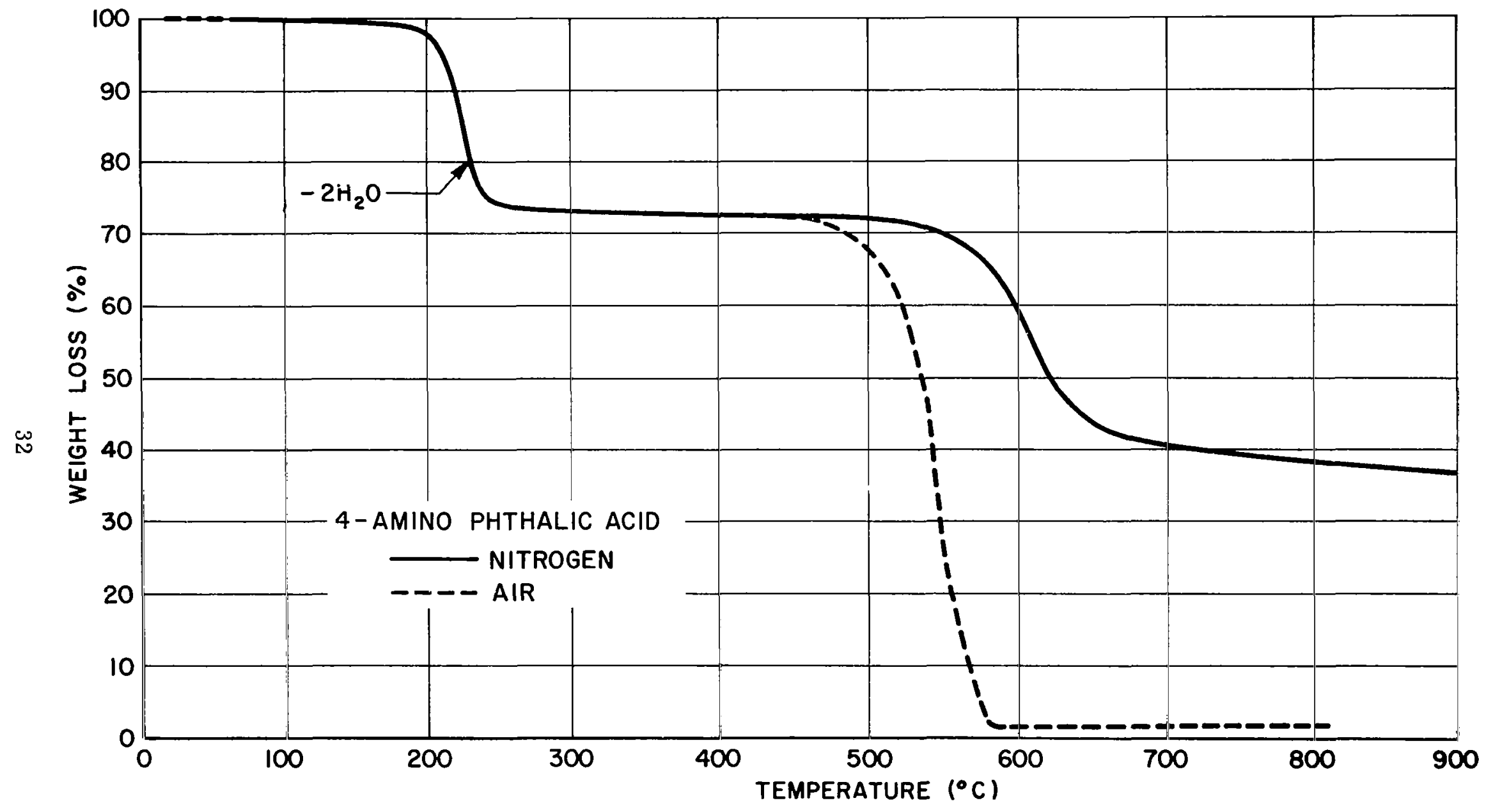

FIGURE 18. T.G.A. $\left(5^{\circ} \mathrm{C} / \mathrm{min}, \mathrm{N}_{2}\right.$ AND AIR) OF 4-AMINO PHTHALIC ACID 


\subsection{T.G.A. Results On Moldings}

At the low end of the thermal stability range were moldings made from aminophthalic acid, at $330^{\circ} \mathrm{C}$. PMDA-TABP (tetraminobenzophenone) was stable to $350^{\circ} \mathrm{C}$. This system should be superior to the PMDA-DAB mixture with more work. Similarly high was the PMDA-TAB (tetramino benzene) but here only the HCl salt of TAB was used. Milled commercial BTDA commercial $D A B$ was thermally more stable at $360^{\circ} \mathrm{C}$ than the equivalent $\mathrm{PMDA}-\mathrm{DAB}, 320^{\circ} \mathrm{C}$, as expected. Similarly, the commercial BTDA commercial DAB in the blended form, at $370^{\circ} \mathrm{C}$, was $20^{\circ} \mathrm{C}$ higher than the equivalent $P M D A-D A B$ mix. For the pure amorphous $B T D A-D A B$ salt,a $10^{\circ} \mathrm{C}$ increase was found over the equivalent PMDA-DAB salt. For milled and blended mixtures the thermal stability definitely increases with purity; salts gave the most thermally stable products. Particularly encouraging were the results for the pure NTCA pure DAB blended mix giving molding stable to $400^{\circ} \mathrm{C}$; for the equivalent crystalline salt, stability as high as $460^{\circ} \mathrm{C}$ was seen, the highest of any molded high temperature plastic made by us.

\subsection{U1trasonic Modulus Results}

U1 trasonic modulus results of the order of magnitude expected with the limited amount of work possible were obtained. For the BTDA-DAB system, a modulus of $0.9 \times 10^{6} \mathrm{psi}$ was achieved. The latter result is gratifyingly high. One might anticipate achieving results as high as $5 \times 10^{6}$ psi with optimization, particularly with somewhat higher molding temperatures.

\subsection{Hardness Results}

For the BTDA-DAB system, a range of Knoop hardness between 14 and $36 \mathrm{~kg} / \mathrm{mm}^{2}$ (100g load) was seen. For the NTCA-DAB mixture rather reproducible hardness, between 27 and $39 \mathrm{~kg} / \mathrm{mm}^{2}$ were achieved.

\subsection{Diametral Strengths}

The only example of high strength found, 14,600 psi, was for a BTDA-DAB specimen. This was a particularly interesting result because general$7 y$ during the molding of the BTDA-DAB composition, polymerization of the purified starting materials appeared very slow so that squeezing out of the die occurred at quite low pressures. With the discovery that polymerization in the PMDA-DAB system was influenced by the presence of acid, the BTDA-DAB composition was allowed to stand in the open air for several days, hopefully to pick up water. The molding behavior was now found to be completely different, producing specimens that appeared to be much superior. Unquestionably acid catalysis of polymerization must be occurring. The best strength result for the NTCA-DAB material, 4,800 psi, was found for the amorphous salt. 


\section{SUMMARY TABLES OF RESULTS}

\section{TABLE I}

TEMPERATURE OF TOP THERMAL STABILITY IN AIR $\left(0.5^{\circ} \mathrm{C} / \mathrm{min}\right)$ OF HOLDINGS OF VARIOUS MIXES AND MONOMERS

$\begin{array}{ll}\text { Commercial PMDA + Commercial DAB - milled } & 320^{\circ} \mathrm{C} \\ \text { Pure aminophthalic acid - monomer } & 330^{\circ} \mathrm{C} \\ \text { Commercial PMDA + Comercial DAB - blended } & 350^{\circ} \mathrm{C} \\ \text { *Commercial PMDA + Pure TABP- salt } & 350^{\circ} \mathrm{C} \\ \text { Commercial PMDA + Commercial DAB - freeze dried } & 350^{\circ} \mathrm{C} \\ \text { Commercial PMDA + Commercial TAB HCl } & 350^{\circ} \mathrm{C} \\ \text { Commercial BTDA + Commercial DAB - milled } & 360^{\circ} \mathrm{C} \\ \text { Commercial BTDA + Commercial DAB - blended } & 370^{\circ} \mathrm{C} \\ \text { Pure PMDA + Pure DAB - salt } & 380^{\circ} \mathrm{C} \\ \text { Pure PMDA + Pure DAB - blended } & 390^{\circ} \mathrm{C} \\ \text { Pure BTDA + Pure DAB - salt } & 390^{\circ} \mathrm{C} \\ \text { Pure NTCDA + Pure DAB - blended } & 400^{\circ} \mathrm{C} \\ \text { Pure PMDA + Pure DAB - freeze dried } & 400^{\circ} \mathrm{C} \\ \text { FIRL DANA - single monomer } & 400^{\circ} \mathrm{C} \\ \text { Pure NTCDA + Commercial DAB - blended } & 470^{\circ} \mathrm{C} \\ \text { Commercial PMDA \& Commercial DAB - salt } & 410^{\circ} \mathrm{C} \\ \text { Pure NTCDA + Pure DAB - salt } & 460^{\circ} \mathrm{C} \\ & \\ & \end{array}$


TABLE II

SUMMARY OF THE MOLDING AND PROPERTIES OF SOME OF THE BETTER SAMPLES OF PMDA+DAB

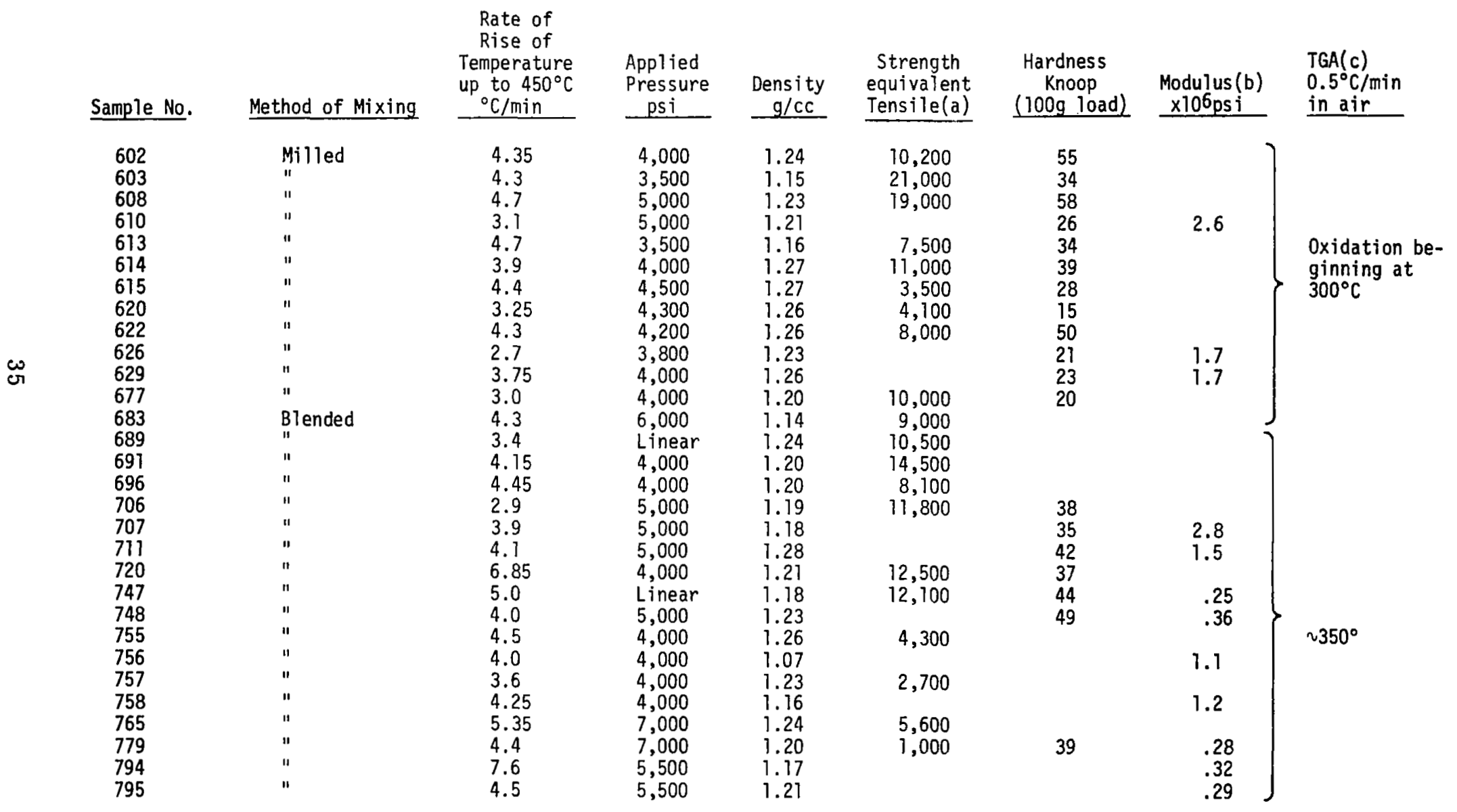

Notes at end of table, page 37 
TABLE II (continued)

SUMMARY OF THE MOLDING AND PROPERTIES OF SOME OF THE BETTER SAMPLES OF PMDA+DAB

\begin{tabular}{|c|c|c|c|c|c|c|c|c|}
\hline Sample No. & Method of Mixing & $\begin{array}{l}\text { Rate of } \\
\text { Rise of } \\
\text { Temperature } \\
\text { up to } 450^{\circ} \mathrm{C} \\
{ }^{\circ} \mathrm{C} / \mathrm{min} \\
\end{array}$ & $\begin{array}{l}\text { Applied } \\
\text { Pressure } \\
\text { psi }\end{array}$ & $\begin{array}{c}\text { Density } \\
\mathrm{g} / \mathrm{CC} \\
\end{array}$ & $\begin{array}{l}\text { Strength } \\
\text { equivalent } \\
\text { Tensile(a) }\end{array}$ & $\begin{array}{c}\text { Hardness } \\
\text { Knoop } \\
(100 \mathrm{~g} \mathrm{load}) \\
\end{array}$ & $\begin{array}{l}\text { ModuTus (b) } \\
\times 10^{6} \mathrm{ps} i \\
\end{array}$ & $\begin{array}{l}\operatorname{TGA}(\mathrm{c}) \\
0.5^{\circ} \mathrm{C} / \mathrm{min} \\
\text { in air } \\
\end{array}$ \\
\hline $\begin{array}{l}800 \\
809 \\
810 \\
820 \\
821(\mathrm{e}) \\
836(\mathrm{e}) \\
881(\mathrm{e}) \\
882(\mathrm{e}) \\
883(\mathrm{e}) \\
921 \\
946 \\
964(\mathrm{~d}) \\
976(\mathrm{~d}) \\
977(\mathrm{~d}) \\
979(\mathrm{~d}) \\
980 \\
986(\mathrm{~d}) \\
987(\mathrm{~d}) \\
1042 \\
1055 \\
1079 \\
1082 \\
1086 \\
1087 \\
1088 \\
1092 \\
1094 \\
1100 \\
1103(\mathrm{~h}) \\
1104 \\
1105\end{array}$ & 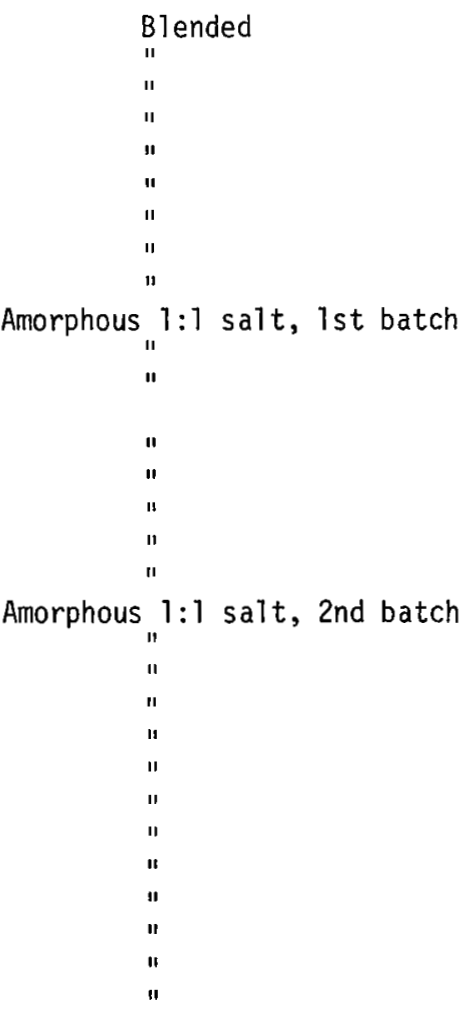 & $\begin{array}{c}5.2 \\
6.5 \\
4.9 \\
4.5 \\
3.5 \\
4.5 \\
2.9 \\
1.9 \\
3.0 \\
44.8 \\
4.3 \\
5.8 \\
11.1 \\
10.0 \\
5.9 \\
6.0 \\
7.0 \\
6.2 \\
6.5 \\
6.5 \\
5.8 \\
5.9 \\
4.3 \\
5.0 \\
5.25 \\
4.1 \\
3.6 \\
3.7 \\
3.3 \\
3.5 \\
3.1\end{array}$ & $\begin{array}{l}6,000 \\
8,000 \\
8,000 \\
\text { Linear } \\
6,000 \\
\text { Linear } \\
5,000 \\
5,000 \\
5,000 \\
\text { Linear } \\
\text { Linear } \\
5,000 \\
4,000 \\
4,000 \\
4,000 \\
5,000 \\
4,000 \\
4,500 \\
4,500 \\
4,000 \\
4,500 \\
4,750 \\
5,500 \\
5,500 \\
5,700 \\
6,000 \\
5,900 \\
5,500 \\
6,300 \\
6,300 \\
6,500\end{array}$ & $\begin{array}{l}1.21 \\
1.21 \\
1.21 \\
1.21 \\
1.25 \\
1.24 \\
1.19 \\
1.20 \\
1.26 \\
1.24 \\
1.17 \\
1.25 \\
1.25 \\
1.21 \\
1.22 \\
1.24 \\
1.26 \\
1.27 \\
1.23 \\
1.12 \\
1.24 \\
1.14 \\
1.27 \\
1.27 \\
1.27 \\
1.23 \\
1.28 \\
1.21 \\
1.29 \\
1.29 \\
1.30\end{array}$ & $\begin{array}{r}8,000 \\
10,700 \\
12,600 \\
3,600 \\
9,600 \\
6,400 \\
12,100 \\
9,000 \\
13,000 \\
5,800 \\
2,200 \\
19,800 \\
14,600 \\
5,300 \\
10,900 \\
12,700 \\
16,300 \\
17,300 \\
4,200 \\
\\
10,300 \\
3,600 \\
8,100 \\
9,200 \\
10,100 \\
3,200 \\
12,300 \\
5,800 \\
9,400 \\
14,300 \\
15,600\end{array}$ & $\begin{array}{l}18 \\
40 \\
43 \\
38 \\
43 \\
40 \\
50 \\
43 \\
47 \\
41 \\
44\end{array}$ & $\begin{array}{l} \\
\\
\\
1.0 \\
1.6 \\
1.00 \\
.97(f) \\
0.86 \\
.58(f) \\
1.12 \\
1.16 \\
\\
0.66 \\
1.00 \\
0.79 \\
0.93 \\
0.91 \\
0.92 \\
.99 \\
1.0 \\
0.40 \\
1.90 \\
1.13 \\
1.12\end{array}$ & $\begin{array}{r}370 \\
390 \\
\\
350 \\
390\end{array}$ \\
\hline
\end{tabular}

Notes at end of table, page 37 
TABLE II (continued)

SUMMARY OF THE MOLDING AND PROPERTIES OF SOME OF THE BETTER SAMPIES OF PMDA DAB

\begin{tabular}{|c|c|c|c|c|c|c|c|c|c|}
\hline Sample No. & Metho & lod of Mixing & $\begin{array}{l}\text { Rate of } \\
\text { Rise of } \\
\text { Temperature } \\
\text { dp to } 450^{\circ} \mathrm{C} \\
{ }^{\circ} \mathrm{C} / \mathrm{min} \\
\end{array}$ & $\begin{array}{l}\text { Applied } \\
\text { Pressure } \\
\text { psi }\end{array}$ & $\begin{array}{c}\text { Density } \\
\mathrm{g} / \mathrm{cc} \\
\end{array}$ & $\begin{array}{l}\text { Strength } \\
\text { equivalent } \\
\text { Tensile(a) } \\
\end{array}$ & $\begin{array}{c}\text { Hardness } \\
\text { Knoop } \\
(100 \mathrm{~g} \text { load })\end{array}$ & $\begin{array}{r}\text { Modulus (b) } \\
\times \quad 106 \text { psi } \\
\end{array}$ & $\begin{array}{l}\text { TGA(c) } \\
0.5^{\circ} \mathrm{C} / \mathrm{min} \\
\text { in air } \\
\end{array}$ \\
\hline $\begin{array}{l}1108 \\
1109 \\
1110 \\
1111 \\
1112 \\
1113 \\
1114 \\
1118 \\
1119 \\
1120\end{array}$ & Amorphous & $\begin{array}{l}1: 1 \text { salt,2nd batch } \\
" 1 \\
" \\
" \\
" \\
" \\
" \\
" \\
" 1\end{array}$ & $\begin{array}{l}2.7 \\
3.5 \\
3.0 \\
3.75 \\
3.5 \\
4.25 \\
3.0 \\
4.25 \\
3.0 \\
3.8\end{array}$ & $\begin{array}{l}6,750 \\
7,000 \\
5,900 \\
6,700 \\
7,300 \\
7,300 \\
7,300 \\
7,500 \\
8,000 \\
8,000\end{array}$ & $\begin{array}{l}1.30 \\
1.32 \\
1.25 \\
1.28 \\
1.30 \\
1.29 \\
1.30 \\
1.27 \\
1.16 \\
1.30\end{array}$ & $\begin{array}{r}15,200 \\
10,200 \\
4,800 \\
8,000 \\
12,000 \\
14,600 \\
9,600 \\
7,400 \\
2,200 \\
12,800\end{array}$ & $\begin{array}{l}43 \\
50 \\
48\end{array}$ & $\begin{array}{l}1.01 \\
1.17 \\
0.88 \\
1.06 \\
1.09 \\
2.00 \\
1.15\end{array}$ & $375^{\circ}$ \\
\hline
\end{tabular}

${ }^{\text {a }}$ By the diametral method

b Sonic method

c Temperature at which weight loss starts

d Strength increases uniformly with modulus for this series

"With carbon fiber "reinforcement" (not followed up, was a quick test only)

$f$ Internal flaws showing sound reflection

9 Highest modulus specimens also have good strength

$h$ went to $490^{\circ} \mathrm{C}$ 
TABLE III

SIGNIFICANT MOLDING AND PROPERTIES OF THE BTDA-DAB AND NTCA ${ }^{\#+D A B}$ SYSTEMS



a- by the diametral method; b- ultrasonic method; c- temperature at which degradation starts 


\section{TABLE IV}

PYRRONE MOLDINGS AS SUPPLIED TO NASA PREPARED FROM PMDA+DAB SALTS

Rate of

Rise of

Temperature

up to $450^{\circ} \mathrm{C}$

Sample No. Salt Type

${ }^{\circ} \mathrm{C} / \mathrm{min}$

$1122 \quad$ Amor
1130
1132
1134
1135
1149 orange
1152
1153
1154
1156
1159
$1167(b)$
$1163(b, c)$
1167
1181
1184
1194

Amorphous 1:1 salt

"

3.3

3.25

3.25

3.25

" 3.25

5.0

$\begin{array}{cr}\text { "1 } & 4.5 \\ 11 & 5.0 \\ 11 & 4.5\end{array}$

5.0
5.0
5.0

5.0

5.0

5.0

5.0
5.0

Applied

Pressure

psi

7,000

6,700

6,700

6,700

6,700

7,500

6,700

7,500

7,500

7,500

7,500

7,500

7,500

7,500

7,500

\begin{tabular}{l}
$\begin{array}{c}\text { Density } \\
\mathrm{g} / \mathrm{cc}\end{array}$ \\
\hline $1.20 \mathrm{~g} / \mathrm{cc}$ \\
1.31 \\
1.31 \\
1.29 \\
1.31 \\
1.29 \\
1.30 \\
1.26 \\
1.31 \\
1.29 \\
1.32 \\
1.28 \\
1.28 \\
1.28 \\
1.27 \\
1.29 \\
1.27
\end{tabular}

Modulus 106 psi

(a)
1.1
1.2
1.2
1.1
1.0
1.1
1.0
1.1
1.3
1.3
1.1
1.1
1.3
1.2
1.0

(a) Modulus not measured, but included because of high hardness

(b) Diametral tensile strength: 11,500 psi for No. 1161, 5,100 psi for No. 1163

(c) Molded to $500^{\circ} \mathrm{C}$
Hardness

$$
\text { (macro-) (micro-) }
$$

("Rockwe11 B") (Knoop) 100g load

$\begin{array}{rr}102 & \\ 94 & 34 \\ 101 & 41 \\ 103 & 50 \\ 94 & \\ 63 & 30 \\ 64 & 52 \\ 62 & 17 \\ 77 & 52 \\ 80 & 17 \\ 88 & 53 \\ 77 & \end{array}$

34
41
50
30
52
17
52
17
53

80 


\section{ANALYTICAL DATA}

Some significant analyses were carried out on the various salts and two moldings therefrom as follows:

ELEMENTAL ANALYSIS (\%) OF $1: 1$ SALTS OF UNPURIFIED MONOMERS ${ }^{b}$

\begin{tabular}{|c|c|c|c|c|c|c|}
\hline & \multicolumn{2}{|c|}{$P^{P M D A-D A B^{a}}$} & \multicolumn{2}{|c|}{ BTDA-Pure DAB } & \multicolumn{2}{|c|}{ NTDA-Pure DAB } \\
\hline & Calc. & Found & Calc. & Found & Calc. & Found \\
\hline C & 56.41 & $\begin{array}{l}56.32 \\
56.41\end{array}$ & 60.84 & $\begin{array}{l}59.37 \\
59.18\end{array}$ & 60.27 & $\begin{array}{l}61.76 \\
61.99\end{array}$ \\
\hline & 4.30 & $\begin{array}{l}4.22 \\
4.30\end{array}$ & 2.47 & $\begin{array}{l}4.53 \\
4.35\end{array}$ & 2.33 & $\begin{array}{l}3.52 \\
3.48\end{array}$ \\
\hline N & 11.96 & $\begin{array}{l}11.84 \\
11.77\end{array}$ & 9.79 & $\begin{array}{l}11.63 \\
11.70\end{array}$ & 10.81 & $\begin{array}{l}10.01 \\
10.12\end{array}$ \\
\hline
\end{tabular}

ELEMENTAL ANALYSES OF TWO MOLDED POLYMER SAMPLES FROM 1:1 PMDA-DAB SALT

\begin{tabular}{crr} 
Molded Polymer, $\mathrm{C}_{33} \mathrm{H}_{8} \mathrm{~N}_{4} \mathrm{O}_{2}$ \\
\hline & \multicolumn{3}{c}{ Calc. } & $\frac{\text { Found }}{\mathrm{b}}$ \\
$\mathrm{C}$ & $\mathbf{7 3 . 3 3}$ & 73.50 \\
$\mathrm{H}$ & 2.22 & 73.01 \\
& & 4.05 \\
$\mathrm{~N}$ & 15.56 & 3.83 \\
& & 15.46 \\
& 15.70
\end{tabular}

${ }^{a}$ Prepared from unpurified monomers

by Galbraith Laboratories

Particulariy encouraging are the close to theoretical results for the impure PMDA-impure DAB salt system. The purification, apparently occurring during the procedure as evidenced by the analysis and by the light color of the compound (rapid darkening occurs with degradation), is much easier by this method than through the use of sublimation and recrystallization.

In general for the moldings, hydrogen analyses are high and oxygen analyses are low (this fits in with an early observation of the lowering of carbonyl peaks in the infra-red spectra on some of our specimens). Nevertheless, these results are unusually close to the theoretical expected. 


\section{SUMMARY CONCLUSIONS}

1. Aromatic tetraamine and tetraacid (or anhydride) monomers can be milled, blended or converted to $1: 1$ salt adducts and reactively hot pressed to Pyrrone moldings.

2. Some estimate of moldability and molding conditions, especially the top molding temperature, can be obtained by thermogravimetric analys is on the starting powders.

3. Use of the linear shrinkage method, which employs a fixed rate of heating and manual or automatic continuous adjustment of applied pressure to maintain a linear shrinkage of the sample from room temperature to top molding temperature allows further estimation of molding conditions.

4. The most favorable molding region for obtaining products of highest density was found by varying the rate of rise of temperature constant applied pressure parameters and holding 1 hour at top temperature.

5. Water loss arising from condensation reactions has not been observed to cause any problems in molding when porous linings are used in the pressing dies. Water appears to diffuse readily through Pyrrone polymers.

6. Unless the density of the product is anomalously high (suggestive of graphitization), the physical properties (strength, modulus, hardness etc.) generally improve with density.

7. Typical molding conditions were a 7,500 psi pressure and a temperature rate of $5^{\circ} \mathrm{C} / \mathrm{min}$ to $450^{\circ} \mathrm{C}$ with a 1 hour hold at $450^{\circ} \mathrm{C}$. Under these conditions a molding is prepared in 145 minutes.

8. Acidic monomers or impurities may enhance the rate of polymerization.

9. Intimate molecular mixing, as afforded through the use of amorphous or crystalline salts of the monomers, increases the rate of polymerization, and improves the thermal stability and reproducibility of the properties of the resulting moldings.

10. The density of the moldings obtained at a particular applied pressure (or the pressure required to achieve a particular density) varied inversely with rate of polymerization, but with crystalline salts rapid polymerization, densification and molding was obtained simultaneously.

11. Other systems similar to Pyrrone polymers may be suited for optimization of molding and performance.

12. Typical physical properties obtained for the PMDA-DAB Pyrrone were: density, $1.29 \mathrm{~g} / \mathrm{cc}$; diametral tensile strength, 10,700 ps $i$; ultrasonic modulus, $1.3 \times 10^{6}$ psi; hardness, 83 Rockwell B; and thermal stability in air (at $\left.0.5^{\circ} \mathrm{C} / \mathrm{min}\right), 400^{\circ} \mathrm{C}$. However, further work will almost certainly improve on all these figures. 


\section{APPENDIX}

\section{PREPARATION OF 4, 5-DINITRO NAPHTHALIC ANHYDRIDE AND ITS REDUCTION TO THE DIAMINE}

4, 5-diaminonaphthalic anhydride is of potential value as a monomer for the preparation of ladder polymers of the Pyrrone type.

Based on information (Ref. 13) that acenaphthene could be oxidized and nitrated in one step to 4, 5 dinitronaphthalic anhydride, the action of conc. nitric acid on the compound was studied.

4, 5 Dinitro-naphthalic anhydride was made therefore in two steps according to the Titerature by first nitrating acenaphthene in acetic acid with conc. $\mathrm{HNO}_{3}$ to give crude 4,5 dinitroacenaph thene $\mathrm{mp}$. 168-172 . (Lit. mp. for purified material is $215^{\circ} \mathrm{C}$ (Ref. 14,15 ).

This was then oxidized by refluxing in glacial acetic acid with sodium dichromate (Ref. 16). The crude product was recrystallized as 1ong shiny pale yellow needies from concentrated nitric acid, mp: $318-319^{\circ} \mathrm{C}$.

$$
\text { C H N }
$$

$\begin{array}{llll}\text { Found: } & 50.69 & 1.64 & 9.69 \% \\ \text { Required for: } \mathrm{C}_{12} \mathrm{H}_{4} \mathrm{~N}_{2} \mathrm{O}_{7} & 50.01 & 1.40 & 9.72 \%\end{array}$

Experiments with acenaphthene and concentrated nitric acid were then continued. It was found that with sufficient nitric acid and a prolonged period of reflux, the same pale yellow compound could be obtained.

IR analysis confirmed that this material was identical with that of the two step method. The IR spectrum was also almost identical with that of an early batch of "diamino-naphthalic anhydride" received through the auspices of NASA, Langley. It was mentioned to us that the nitro compound was not easy to reduce. Later we received a batch that seemed to be correct.

After trying a number of methods, it was found that al though slow hydrogenation could be achieved at 50 psi with PtO catalyst in ethanol, better was transfer hydrogenation using cyclohexene as dohor with $10 \% \mathrm{Pd}$ on charcoal catalyst. The course of the reduction could be followed by the liberation of water which was collected in a Bidwell trap. Theoretical amounts were obtained. 

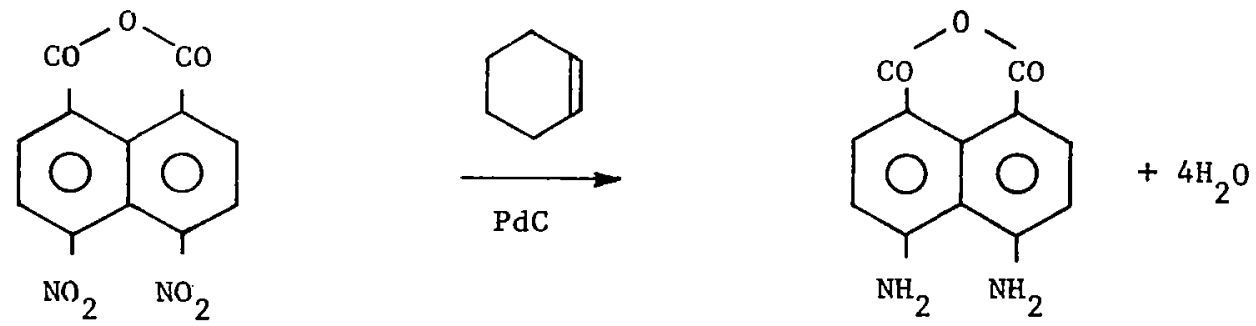

The product, difficult to work up, was separated from the catalyst by solution in DMF or DMSO and then precipitated as a fine green, difficult to filter, solid by dilution with water.

At this time we received from $L$. A. Jones, North Carolina State University, a sample of dimethyl 4,5-diamino-naphthalate (verified by analysis) and this on hydrolysis with alkali and subsequent acidification of the solution with acetic acid gave a green solid similar in appearance to our material.

Found:

C H N

Diamino naphthalic acid,
$\mathrm{C}_{12} \mathrm{H}_{10} \mathrm{~N}_{2} \mathrm{O}_{4}$
59.74
3.70
$11.64 \%$
Requires
58.53
$4.09 \quad 11.37 \%$

Comparison of the IR spectra of the two products showed that they were practically the same although the analysis shown below of the transfer hydrogenation product was nearer that of the anhydride.

C $\mathrm{H} \quad \mathrm{N}$
Found:
Diamino naphthalic an-
62.58
$3.66 \quad 11.00 \%$
hydride, $\mathrm{C}_{12} \mathrm{H}_{8} \mathrm{~N}_{2} \mathrm{O}_{3}$
Requires:
$63.15 \quad 3.53 \quad 12.27 \%$

Because the transfer hydrogenation method involves a rather laborious work up and failed to work in one run due possibly to catalyst poisoning, reduction with stannous chloride was also investigated. This was found to be a practical method and much easier to work up. Material made by this method was ochre in color but gave the same IR spectrum as the above two products and analyzed as follows:
Found:
$\begin{array}{ccc}\mathrm{C} & \mathrm{H} & \mathrm{N} \\ 60.90 & 3.44 & 12.93 \%\end{array}$

This analysis is intermediate between that of the diamino anhydride and that of the diamino dicaboxylic acid. That the compounds made are basically the same is shown by their IR spectra and their behavior on thermogravimetric 
analysis. The presence of an anhydride group and two amine groups in the same molecule is apparently leading at some stage in the preparation and work up to a certain amount of self condensation. This is indicated by the non-crystalline nature of the product, checked by X-ray diffraction methods, the variation of color with the method of preparation and work up, and its lack of solubility in any but the most powerful organic solvents. Analytical difficulties reported to us, may be explained by polymerization during analysis and the variable results may be indicative of semicondensed material.

Thus the ochre colored stannous chloride product analyzes reasonably well for the amide:

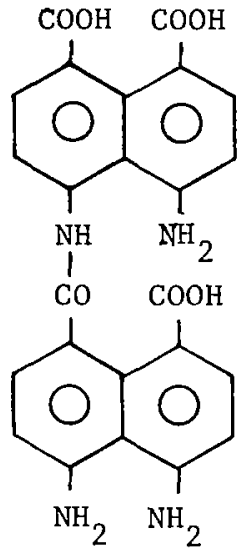

which requires:

C

$\mathrm{H} \quad \mathrm{N}$

$60.75 \quad 3.82 \quad 11.81 \%$
found:
60.90
3.44
$12.93 \%$

To summarize, it has been found that diamino naphthalic anhydride appears to be too reactive a monomer to be isolatable as such. The compounds made are dimers or higher oligomers containing structures of the type shown above.

We also were kindly supplied with a sample (again from L. A. Jones) of dimethyl 4-aminonaphthalate, which analyzed correctly, and this was hydrolyzed by alkali to give, on acidification with acetic acid a bright yellow orange, easily filterable solid. This compound analyzed quite well for the mono-amino naphthalic anhydride but may again be a dimer, etc., of the same empirical formula.

$\begin{array}{lccc} & \mathrm{C} & \mathrm{H} & \mathrm{N} \\ \begin{array}{l}\text { Found: } \\ \mathrm{C}_{72} \mathrm{H}_{7} \mathrm{NO}_{3} \text { Mono-amino }\end{array} & 67.26 & 3.42 & 6.43 \% \\ \begin{array}{l}\text { naphthalic an- } \\ \text { hydride }\end{array} & 67.60 & 3.31 & 6.5 \%\end{array}$


Thermogravimetric analys is of this material showed that it has promise of yielding a high temperature polymer. We have subsequently returned to the preparation of dimethyl 4,5-dinitronaphthalate as detailed in Ref. 13. This can be reduced using cyclohexene and palladium charcoal in refluxing ethanol to give a product identical with diamino naphthalic acid dimethyl ester. This product, is more readily isolatable than the product from reduction of dinitro naphthalic anhydride; furthermore, it can be easily purified by crystallization from a variety of solvents.

Hydrolys is of the amino ester by refluxing aqueous methanolic sodium hydroxide with subsequent acidification of the hot solution with glacial acetic acid gave a nicely crystalline olive green product identical by $1 R$ analysis with previously made "diamino naphthalic anhydride."

This method via the ester is now the preferred route. 


\section{REFERENCES}

1. B. G. Kimmel and L. E. Karre, "Preparation and Characterization of the Pyrrones as Thermal Structural Materials." Report \#P69-112, NASA CR-66853, 1969.

2. P. E. D. Morgan and E. Scala, "High Density Oxides by Decomposition Pressure Sintering of Hydroxides," Proc. Int1. Conf. on Sintering and Related Phenomena, Notre Dame, Indiana, June 1965, Pub1., 1967, Gordon and Breach, N. Y., Ed. G. C. Kuczynski.

3. P. E. D. Morgan, "Superplasticity in Ceramics," in "U1trafine-Grain Ceramics" Syracuse University Press 1970, p. 251-271.

4. A. Rudnick, A. R. Hunter and F. C. Holden, "An Analys is of the Diametral Compression Test," Mat. Res. \& Stand. 3 [4] 283-289 (1963).

5. R. M. Spriggs, L. A. Brisette and T. Vasilos, "Tensile Strengths of Dense Polycrystalline Ceramics by the Diametral Compression Test," Mat. Res. \& Stand. 4 [5] 218-220 (1964).

6. R. L. Van Deusen, J. Polymer Sci., B4, 211 (1966).

7. R. L. Van Deusen, 0. K. Goins and A. J. Sicree, J. Polymer Sci., $A-1,6,1777$ (1968).

8. W. G. Gloor, Polymer Preprints (Am. Chem. Soc.), 9, No. 2, 1174 (1968).

9. A. H. Frazer and W. Memeger, Jr., Polymer Preprints, 9, No. 2, 1150 (1968).

10. Charles T. Hughes, "Preparation and Characterization of Low DP End-Capped Pyrrone Moldings," NASA CR-1633, 1970.

11. G. B. Crippa and P. Galimberti, Gazz Chim. Italiana 63, 81-96 (1933).

12. F. E. Arnold and R. L. Van Deusen, "Poly (perimidine-tetrayls)," J. Polymer Sci., pt. B, vol. 6, No. 11, Nov. 1968, pp. 815-819.

13. Lewis A. Jones, Charles A. Joyner, Hong Ki Kim, and Robert A. Kyff, "Acenaphthene. I. The Preparation of Derivatives of 4,5-Diamino Naphthalic Anhydride," Can. J. Chem. (In Press).

14. M. M. Dashevskii, and Z. P. Malevannaya, Zh. Organ. Khim 1(7) 1272-6 (1965) Chem. Abs., 63 14782f.

15. F. Sachs, G. Mosebach, Ber. 44, 2852 (1911).

16. F. Mayer, and W. Kaufman, Ber. 53, 289 (1920). 